\title{
Molten salts database for energy applications
}

\author{
R. Serrano-López ${ }^{\mathrm{a}, *}$, J. Fradera ${ }^{\mathrm{a}}, \mathrm{S}$. Cuesta-López $^{\mathrm{a}, * *}$ \\ ${ }^{a}$ Science and Technology Park. I+D $+I$ Building. Room 63. Plaza Misael Bañuelos s/n, 09001, Burgos (Spain)
}

\begin{abstract}
The growing interest in energy applications of molten salts is justified by several of their properties. Their possibilities of usage as a coolant, heat transfer fluid or heat storage substrate, require thermo-hydrodynamic refined calculations. Many researchers are using simulation techniques, such as Computational Fluid Dynamics (CFD) for their projects or conceptual designs. The aim of this work is providing a review of basic properties (density, viscosity, thermal conductivity and heat capacity) of the most common and referred salt mixtures. After checking data, tabulated and graphical outputs are given in order to offer the most suitable available values to be used as input parameters for other calculations or simulations. The reviewed values show a general scattering in characterization, mainly in thermal properties. This disagreement suggests that, in several cases, new studies must be started (and even new measurement techniques should be developed) to obtain accurate values.
\end{abstract}

Keywords: properties, molten salt, CFD, CSP, coolants, energy

Nomenclature
$\begin{array}{cl}\text { Symbols } & \text { and Units } \\ \mathrm{T} & \text { Temperature, }{ }^{\circ} \mathrm{K} \\ \text { M.P. } & \text { Melting point, }{ }^{\circ} \mathrm{K} \\ \mathrm{v} & \text { Velocity, } \mathrm{m} / \mathrm{s} \\ \rho & \text { Density, } \mathrm{kg} / \mathrm{m}^{3} \\ \eta & \text { Dynamic viscosity, Pa.s } \\ \nu=\frac{\eta}{\rho} & \text { Kinematic viscosity, } \mathrm{m}^{2} / \mathrm{s} \\ \lambda & \text { Thermal conductivity, } \mathrm{W} /\left(\mathrm{m} \cdot{ }^{\circ} \mathrm{K}\right) \\ C p & \text { Heat Capacity, } \mathrm{J} /\left(\mathrm{kg} \cdot{ }^{\circ} \mathrm{K}\right)\end{array}$

${ }^{*}$ Corresponding author. Tel: $(+34) 947258907$. Universidad de Burgos, Spain.

** Principal corresponding author. Tel: (+34) 947259062. Universidad de Burgos, Spain.

Email addresses: robertosl@ubu.es

(R. Serrano-López), jfradera@ubu.es (J. Fradera), scuesta@ubu.es (S. Cuesta-López)

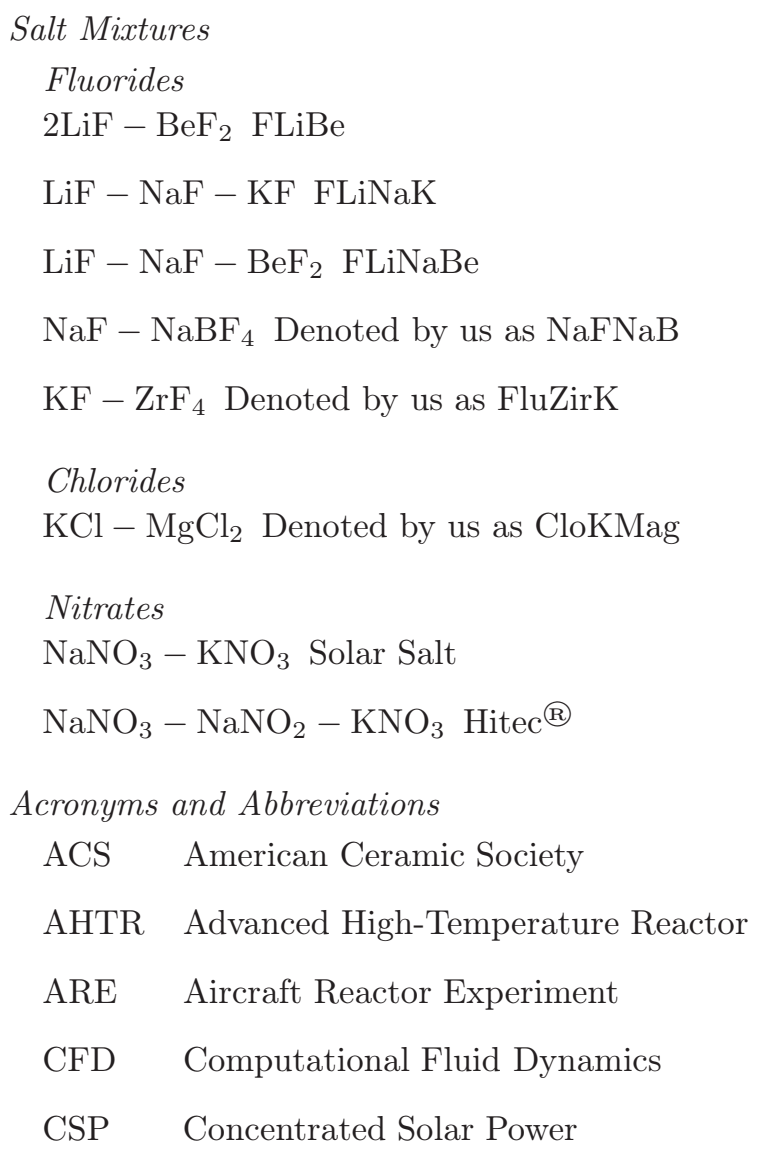




\author{
CSPonD Concentrated Solar Power on Demand \\ FHR Fluoride Salt Cooled High-Temperature \\ Reactor \\ HR Homogenueus Reactor \\ HTS Heat Transfer Fluid \\ HTX Heat Exchanger \\ IHX Intermediate Heat Exchanger \\ INL Idaho National Laboratory \\ MSRE Molten Salt Reactor Experiment \\ NREL National Renewable Energy Laboratory \\ ORNL Oak Ridge National Laboratory \\ TES Thermal Energy Storage
}

\section{Introduction}

Different heat transfer systems are being studied around the use of molten salt technology as working fluid. The initial development of salts features and use was carried out at Oak Ridge National Laboratory (ORNL) for aircraft propulsion purposes [1]. The ORNL team build demonstration reactors between 1950's and 1960's (ARE and MSRE), and continued their research during several years in order to design a Molten Salt Breeder Reactor [2]. During these years, a great amount of technical reports about salt candidates and tests were written, revised and archived, including a review of the final experimental successes [3]. The experience collected in that decades has been the subject of a renewed interest, due to potential advantages of liquid salt coolants in different ways [1, 4, 5]:

- high volumetric heat capacity,

- high boiling point and low vapor pressure,

- no undesirable chemical exothermic reactions between different zones of energy plants and power cycle coolants (core, heat exchange loop),

- optical transparency during inspection operations,

- ability to dissolve actinides,

- great insensitivity to radiations.
Molten salts also offer nuclear breeding capability by optimizing mixture and giving a on-line processing to the fuel salt carrier [2], and certain compositions can be used as neutron moderators (e.g. those containing Be). The advantages of salt coolants enable them for being used in heat transport loops, and would open new nuclear and non-nuclear applications [4, 6- 8] :

- fission power plants (both liquid or solid fuel, mainly in high-temperature reactors),

- fusion or hybrid reactors,

- hydrogen production,

- long distance heat transport,

- nuclear fuel reprocessing,

- chemical industry,

- oil refineries,

- shale oil processing, etc.

There are also advanced studies about the use of fluids in the power cycle, transport and heat storage in high-efficiency solar power facilities [9 12]. Even future nuclear-propelled space aircrafts are being now studied around the same concepts [13]. Developments achieved in every of these fields could be generalized for civil and industrial uses in the future with the benefits of scale economy and standardization of processes.

The present work intends to be a thorough review of the current knowledge on molten salt properties, with the aim of giving to the researcher a key to evaluate their behavior. These data may be of interest in both experimental as numerical simulation tasks, such Computational Fluid Dynamics (CFD), and can be applied for thermal exchange, storage or piping systems [14].

\section{Background}

As has already be mentioned, the initial studies about salt properties were developed by scientists involved in chain reactions. Harold Urey, a nuclear chemist, and Eugene Wigner, a theoretical physicist, both implicated in the Manhattan Project, were the early promoters of the Homogeneous Reactors (HR). First molten fluorides ideas came into the chain reaction community by 1945 [15]. Therefore, ORNL Chemical Technology 
Division was searching since the late forties for a homogeneous liquid solution suitable for use as a fuel for the aircraft reactor of the Aircraft Nuclear Propulsion Project. A fluid able for being used at high temperature and low pressure was needed, with the requirement of radiation stability and actinides solubility [16]. It is assumed that Edward Bettis and Raymond Clare Briant were the persons who, years later, cut the Gordian knot by suggesting again the use of fluorides with the Molten Salt Reactor concept [17, 18].

Although initial tests with HR were developed through sulphates, the pressure of Cold War shoved US Atomic Energy Commission to start the Aircraft Nuclear Propulsion Program [18]. In this case, new requirements were solved by the use of liquid alkali fluorides instead of solid fuel rods. Several developments in hi-tech materials and salt chemistry (e.g. dry fluorination) were added to knowledge during this experiences. From the very beginning, structural materials corrosion appeared as the most important issue to resolve [16]. Lithium and beryllium salts were very early considered to allow self-moderated fuels [19], and FLiNaK appeared simultaneously in heat transfer studies 20, 21]. Using graphs and charts, Poppendinck [22] analyzed some useful properties for different coolants, including molten salts.

During the forties and the fifties some reports were also written for ceramic applications (see, e.g., [23 28]). Since 1964, there have been different compilations of phase equilibria diagrams at the National Bureau of Standards (edited by ACS) [29]. This multi-volume work is continuously improved performing the cumulative specialized ACerS-NIST Phase Equilibria database (ACerS-NIST Phase Equilibria Diagrams), which is also on-line nowadays (http:// ceramics.org/publications-and-resources/ phase-equilibria-diagrams).

Ricci [30] and Thoma [31] made the first efforts to compile specific available equilibria data for different kind of chemical systems for nuclear applications. Maybe the first review of fused salt properties was made by Grimes [32] for nuclear reactors coolants (FLiBe, FLiNaK, and FLiNaBe). Grimes included measured values and correlations for Melting Point (MP), density $(\rho)$, heat capacity $(C p)$ and viscosity $(\eta)$ for these salts.

During sixties, several achievements were made around the Molten Salt Reactor concept, including the referred use of salts as coolants in heat exchange systems. Most of the reports came from ORNL Divisions. Blanke et al. [33] studied Li and Be fluorides density and viscosity. Grimes [34] gave some values for FLiBe [66-34 \%] at $854^{\circ} \mathrm{K}(\rho, C p, \eta, \lambda)$. Thereafter, Grimes 35] discussed the requirements of coolant fluids for the MSBR providing values for $\mathrm{NaFNaB}$ [4-96 \%] and FLiNaBe [5-56-42\%, and 26$41-36 \%$ ] among other salt mixtures at $727^{\circ} \mathrm{K}(\rho$, $C p, \eta, \lambda)$ 35

Cantor 36 40 studies are also a classical reference for salt properties. Two mixtures were listed in 1968 [37], FLiBe [66-34 \%] and NaFNaB [92$89 \%$ ], based in a critical review of own and other measurements. Then FLiBe was again studied in 1969 [39], giving density and viscosity correlations for different melt compositions. Some fluoride mixtures (FLiBe, NaFNaB) were revised also by Cantor in 1973 [40].

McDuffie et al. [41] reviewed again coolant requirements for heat exchange for nuclear technology purposes, summarizing physical properties of different mixes of fluorides, chlorides, nitrates, and fluoborates. Similar works were conducted by Sanders (1971) 42] (NaFNaB, FLiBe, FLiNaK, nitrates), and Kelmers et al. (1976) [43] (NaFNaB, FLiBe). The use of low-cost molten salts as heat transfer fluids and their potential for thermal energy storage were also early discussed; Silverman and Engel made a review of Solar Salt and Hitec ${ }^{\circledR}$ capabilities in 1977 [44].

Janz started in 1968 a huge effort to compile a general database for molten salts [45, 46] relevant to energy storage [47 49]. Reports were published by the Office of Standard Reference Data at the National Bureau of Standards (OSRD-NBS), including a comprehensive compilation of eutectic compositions for salts. This series made a critical review of measurement methods and correlations, and were progressively written and published between 1968 and 1981.

Janz also worked in cumulative results for the salts properties between 1972 and 1983 (the Molten Salts Standards Program) [50-56]. This general database, subsequently reprinted and summarized in 1988 [57], is widely used today for any purpose due to its updated recommendations and reexamined best values for making density and viscosity predictions [58].

Lately, an important assessment of some liquid salts was conducted by Williams et al. in 2006 at ORNL [59 61], focusing their works in the Advanced High-Temperature Reactor (AHTR) ini- 
tial concept development (primary and secondary coolants). This work included classical Janz, Cantor and ORNL entrances in most usual salt mixtures for nuclear reactors. However, Be-containing salts were in these case excluded because of their higher cost and toxicity. These studies also advised about taking into account $\mathrm{LiCl}-\mathrm{KCl}-\mathrm{MgCl}_{2}$ due to its low-cost. Further, Williams included additional measurements for relatively unexplored $\mathrm{Zr}$ and Al fluoride salts 62].

During these last years, Winconsin-Madison University has joined with Shell Company to perform the on-line Molten Salts Database. This American institution is currently working to maximize molten salts potential in energy issues (in support of fusion reactor and Very-High-Temperature Reactor (VHTR) concepts), with emphasis in FLiNaK and CloKMag mixtures 63. Additional efforts are being conducted in the Idaho National Laboratory (INL) 64, 65].

Other institutions have funded knowledge on liquid salts behavior and selection criteria, like the International Atomic Energy Agency (IAEA) 66], the International Science and Technology Center (ISTC) by the support of European Community [67, and the European Commission through ALISIA (Assessment of LIquid Salts for Innovative Applications) [8].

\section{Selection of salts}

The advantages of molten salts as Heat Transfer Fluid (HTF) and Thermal Storage System (TES) promise a great development during next decades. The cost for the required volume of heat exchangers and pumps are highly reduced by the use of liquid salts instead of other coolants due to their higher volumetric heat capacity without the need of pressurizing. It has been reported that melting points and heat capacities increase in the following order: nitrates, chlorides, carbonates, and fluorides [68. In any case, fluid salts provide the potential for improved heat transfer and reduced pumping powers and volume of the heat exchanger compared with helium. Molten salts have a $25 \%$ higher volumetric heat capacity than pressurized water, nearly fivetimes that of liquid sodium [69], and more than twice than lead or lead-bismuth eutectic [6, 70].

Long term corrosion, compatibility with available structural materials, potential toxicity and final costs are key research issues. In some cases, stability requirements reduce the number of chance possibilities; in others, avoid freezing maybe the critical issue [71]. So the salt must be properly selected in order to agree the particular conditions of use.

Be mixtures require very special and expensive handling efforts due to toxicity, and so has been discarded from some reports 61]. For this reason FLiNaK has emerged, in several cases, as main alternative because of its low toxicity, excellent heat transfer properties, and chemical properties similar to those of FLiBe [72]. In nuclear applications, purity of $\mathrm{Li}$ is an additional requirement with primary coolants (at least $99,995 \%$ of ${ }^{7} \mathrm{Li}$ is needed to avoid decrease reactivity feedback, due to tritium generation by the neutron absorption of ${ }^{6} \mathrm{Li}$ isotope), and even with secondary coolants in case of a leak at Heat Exchanger (HTX) loop. For this reason other possibilities (other than FLiBe and FLiNaK) are now being explored for the latest versions of VHTR Intermediate Heat Exchanger (IHX), e.g. FluZirK liquid salt, wich has a relatively low toxicity, and does not include Li 73]. Williams discussed the influence of the price of the components with different salt mixtures [61]. His conclusions determined that magnesium chlorides are the least expensive of all, while fluorides, fluoroborates and Li-containing mixtures increase the price of the coolant (Williams excluded Be because of the same issues explained above). Hence, with a multi-criteria analysis including technical and economic factors, an additional study of $\mathrm{MgCl}_{2}$-containing salts should be recommended (despite of inferior heat-transfer metrics of chlorides). The ideas previously summarized have suggested both FluZirK and CloKMag as possible working fluids in heat transfer piping systems. Several studies have been focused towards the behavior of the new potential fluids [74 77].

Zirconium fluorides were used in the past given the fact of their high solubility for actinides and oxygen getter. In addition, $\mathrm{Zr}$ has been proposed to mitigate materials corrosion by controlling the red-ox potential of the salts, but the activation products complicate their ability to be used as primary coolants 63. Heavy halide salts (bromides, iodides) have poor heat transfer metrics 61], but chlorides, as well as nitrites and nitrates may be useful respect to raw materials cost. Oxygencontaining salts, such as nitrite-nitrate salt mixtures are not suitable as primary coolants in nuclear plants 78 . Chlorides were avoided in the past due to corrosion, but there are renewed expectatives around them in AHTR design. 
New salt compositions are probably going to be tested for large scale energy systems, and even nanofluids could emerge as future solutions increasing $C p$ of usual base fluids by the addition of nanoparticles in low percentages 79]. However, after a literature survey, classical mixtures appear in most of conceptual and commercial designs of both nuclear and non nuclear applications. For instance, recent reports [8, 66, 80] have reviewed most usual proposals for nuclear reactors, including GEN-IV concepts.

Synergistic efforts in heat transport liquids are now being developed for both molten and liquid salt concepts, especially taking into account new possibilities in TES and Concentrated Solar power (CSP) technologies [10, 81]. The need of decarbonizing the energy mix current century has attracted and renewed the attention to different studies started decades ago, when nuclear and aerospace research was growing up [82, 83]. In the other hand, first commercial CSP-TES systems are using common compositions as working fluids, whose behavior is well known and have more competitive cost. These salt mixtures take in advance the accrued accomplishments since middle past century in heat transfer and storage, looking for compromise between thermal efficiency and economy 71]. For CSP and TES, the raw materials cost of nitrogenbased salt-compositions makes them currently the most competitive solution (Solar salt and Hitec ${ }^{\circledR}$ ). Some Li-containing mixtures and other additives are also been investigated and patented for future development [84, 85]. In this case nitrate-nitrites are not only cheaper, but also much less corrosive than fluorides or chlorides, while thermal capabilities could be improved on a compromise solution in the medium term.

As have been mentioned in section 2, several experimental works have been carried out for fluoride, chloride an nitrate salts (single, binary and ternary mixtures) since the ARE project in ORNL. The working fluid selection must take into account different circumstances, so there are different candidate salt mixtures for different applications. Firstly, in case of primary nuclear coolant the ideal salt must have: (i) a melting point well below the coldest point in the circuit, (ii) a boiling point and thermal stability well above any credible accident condition temperatures, (iii) a low vapor pressure, (iv) a low viscosity at operating temperature, (v) a large heat capacity, good thermal conductivity, low Prandtl number, and (vi) a large change in spe- cific volume with temperature to effectively drive natural circulation cooling. Chemical and neutron behavior may be also constraints in the fluid selection, so that the neutron-absorption cross section of coolant should be lower enough to guarantee stability under radiation. Moreover, the coolant selection have to ensure compatibility with structural materials of core, loop, and piping system [86].

Fuel-salts require in addition an adequate actinide solubility at the working core temperature, and the outlined features have also to be properly identified for the fuel mixture.

Secondary coolants have no nuclear constraints, and the evaluation criteria is mainly based on heat transport performance. But the same chemical system should be employed in both sides of HTX, so that compatibility of structural alloy with two different species is not required at the working temperature. Therefore, requirements are simpler than for primary coolant: low melting and boiling point, low vapor pressure, thermal stability and conductivity, low viscosity, large heat capacity, material compability, and preferably non/low toxicity. Some of them have been discussed as "Figure of merits" (FOM) by Idaho National Laboratory (INL) [87]. Whatever function proposed (primary, fuel or secondary coolant), commercial availability and industrial processing cost must also be take in account. The cost and especial care demanded for Be handling have been also referred occasionally by experimental researchers as an additional use constraint, at least during initial knowledge development of high temperatures performance [59, 61].

As oxygen-containing salts, nitrite-nitrate salt mixtures are not suitable as primary coolants [78]. Although latest reports agree on avoid chlorides for MSR, and nitrites-nitrates are also unlisted [80], both of them are frequently referred for heat exchange coolants in energy applications. Williams 61] recommended the ternary eutectic $\mathrm{LiCl}-\mathrm{KCl}-\mathrm{MgCl}_{2}$ for additional study because of its potential and raw-material cost, and this salt has been recognized also by Beneš and Konings $[80$, 88 as FLiNaK alternative HTF in the VHTR concept. As mentioned above, current Fluoride-SaltCooled High-Temperature (FHR) version includes FluZirK as secondary coolant [73].

This section have checked the most important criteria used for molten salt selection, that can be briefly summarized in the following general ideas:

- high volumetric heat capacity compared with 
other coolants

- mandatory ${ }^{7} \mathrm{Li}$ purity requirements in nuclear applications

- the cost is lower for chlorides, and higher for fluorides, fluorobotaes and Li or Be containing mixtures

- Zr provides actinides solubility, oxygen getter capability and red-ox control to salt mixtures, but also have undesirable activation products

- O-containing salts are not suitable as primary coolants

- Zr-fluorides are also being studied as secondary coolants, and chlorides may be a low cost alternative to take into account.

\section{Molten salt thermo-physical properties}

In this section, a review of the most relevant thermo-physical properties for design calculations is shown for the most common and recent coolant or HTS composition choices:

1. FLUORIDES: 2LiF-BeF 2 , (hereafter FLiBe), LiF-NaF-KF (hereafter FLiNaK), LiF-NaF$\mathrm{BeF}_{2}$ (hereafter FLiNaBe), NaF-NaBF 4 (hereafter $\mathrm{NaFNaB}$ ), $\mathrm{KF}-\mathrm{ZrF}_{4}$ (hereafter FluZirK)

2. CHLORIDES: KCl- $\mathrm{MgCl}_{2}$ (hereafter CloK$\mathrm{Mag})$

3. NITRATES: $\mathrm{NaNO}_{3}-\mathrm{KNO}_{3}$ (hereafter Solar Salt), and $\mathrm{NaNO}_{3}-\mathrm{NaNO}_{2}-\mathrm{KNO}_{3}$ (hereafter Hitec $^{\circledR}$ )

Selected properties, by order, are summarized for each salt mixture: melting point, density, viscosity, heat capacity, thermal conductivity. Most usual molar compositions are shown in brackets, in Table 1. When available, possible differences have been checked by using different compositions of the same salt by the same work or author, in order to analyze its behavior in molar terms and the differences among the temperature range of measurement.

Phase diagrams and useful properties have been also recently reviewed by Beneš and Konings 80 , 88] for nuclear fission applications, including critical discussion of recent values and measurements of FLiBe, FLiNaK and NaFNaB.

The currently useful mixtures for solar energy are mainly nitrates and nitrites. Beneš et al. 89] used a encapsulation technique with Solar Salt, measuring phase diagram. Ferri et al. proposed selected properties of Solar Salt in RELAP5-3D code for solar parabolic collectors [90], and Bauer et al. reviewed thermo-physical correlations 91]. Both Solar Salt and Hitec ${ }^{\circledR}$ mixtures have been used in other heat transfer investigations [71, 79, 92 94].

Other particular references are listed for each property, in order to make a complete review of the cases. The general procedure has involved a global plot of all the correlations found, verifying consistency and agreement among them. The aim of this analysis is to create a set of physical properties for technical use in system codes, computational simulations, or experimental workbenches. Data may be also used to observe dispersion and agreement in properties predictions, before make decisions on critical parameters of design in energy projects.

\subsection{Melting point (M.P., ${ }^{\circ} \mathrm{K}$ )}

As has already been commented, phase diagrams for molten salts have been continuously investigated and reviewed in other to detect the most useful compositions for each mixture. Table 1 shows different values for melting point parameter for selected or more common molar compositions. In the case of FLiNaBe there are not many experimental values for the usually referred compositions (0.31-0.31$0.38)$ or $(0.33-0.33-0.33)$.

\subsection{Density $\left(\rho, \mathrm{kg} / \mathrm{m}^{3}\right)$}

In general, a good agreement is verified by all selected mixtures for density correlations. Recommended values are summarized in Table 2 and Fig. 4. Density of FLiBe has been studied and experimented for different compositions since 1956 . The slope of the temperature function in the reviewed bibliography agrees with very little variation. Changes in molar percentages do not suppose great differences (e.g., Cantor et al. [39], Janz et al. 51], Powers et al. 100]), with the exception of values offered by Grimes et al. [32] for 50\%-50\% molar mixture, and recently cited by Korkut and Hançerlioğulları 101]. In this case, a significant disagreement is observed, and correlated values are apparently too large, and the deviation from average is over $11.8 \%$.

The standard molar composition (0.66-0.34) has been correlated by Blanke et al. 33], Cantor et al. 37] and [40]. Cantor [40] is recommended for 
Table 1:

Melting point $\left({ }^{\circ} \mathrm{K}\right)$ proposed or used by different authors for all the studied salts.

\begin{tabular}{|c|c|c|c|c|c|c|c|c|}
\hline Salt mixture & FLiBe & FLiNaK & FLiNaBe & $\mathrm{NaFNaB}$ & FluZirK & CloKMag & Solar Salt & Hitec ${ }^{\circledR}$ \\
\hline Usual Composition & $\begin{array}{l}(0.66- \\
-0.34)\end{array}$ & $\begin{array}{c}(0.465-0.115- \\
-0.42)\end{array}$ & $\begin{array}{c}(0.31-0.31- \\
-0.38)\end{array}$ & $\begin{array}{l}(0.08- \\
-0.92)\end{array}$ & $\begin{array}{l}(0.58- \\
-0.42)\end{array}$ & $\begin{array}{l}(0.68- \\
-0.32)\end{array}$ & $\begin{array}{l}(0.66- \\
-0.34)\end{array}$ & $\begin{array}{c}(0.07-0.49- \\
-0.44)\end{array}$ \\
\hline Hoffman and Lones (1955) 21] & & 727.4 & & & & & & \\
\hline Cohen and Jones (1957) 95 & & 727 & & & & & & \\
\hline Grimes et al. (1958) 32] & & 727 & 611 & & & & & \\
\hline Thoma (1959) 31 & 727 & 727 & 588 & & 663 & & & \\
\hline Cantor et al. (1968) 37 & 731 & & & 658 & & & & \\
\hline Barton et al. (1971) 96 & & & & 654 & & & & \\
\hline Janz et al. (1972) 50 & & & & & & & 495 & \\
\hline Cantor (1973) 40] & & & & 658 & & & & \\
\hline Janz et al. (1974) 51 & 731.9 & & & 657 & & & & \\
\hline Janz et al. (1975) 52] & & & & & & 699 & & \\
\hline Janz et al. (1978) 47 & 729 & 727 & & 657 & 693 & 710 & & \\
\hline Vriesema (1979) 97] & & 727 & & & & & & \\
\hline Janz and Tomkins (1981) 49] & & 727 & & & & 708 & & 415 \\
\hline Abe et al. (1981) 98 & 732.1 & & & & & & & \\
\hline Janz and Tomkins (1983) [56 & & & & 657 & & & & \\
\hline Mlynariková et al. (2008) 99] & & & & 658.7 & & & & \\
\hline Beneš et al. (2010) [89] & & & & & & & 496 & \\
\hline
\end{tabular}


use, in agreement with Beneš and Konings [80]. However, this last work does not offer the correct temperature function, differing from the original proposal. So best values are obtained for the range $\mathrm{T} \in[788-1094]$ (see Eq. 1). The deviation from the average is around $0.89 \%$ for the mentioned selected correlation, while the global standard deviation for the three plotted values (Fig. 1a) is about 17.3 .

$$
\rho\left(\mathrm{kg} / \mathrm{m}^{3}\right)=2413.03-0.4884 \cdot \mathrm{T}\left({ }^{\circ} \mathrm{K}\right)
$$

The density of eutectic FLiNaK has been experimentally measured and estimated in different occasions, as reported by Grimes et al. 32., Janz and Tomkins [49], Chrenková et al. 102], Cibulkova et al. 103 and Salanne et al. 104 for several temperature ranges. Williams et al. 60], Ambrosek et al. [105], and Korkut and Hançerlioğulları [101] used Grimes et al. as a reference. However, and as suggested by Beneš and Konings 88, data of Chrenková et al. are near and parallel to ideal density behavior (lightly minor than ideal). Although Salanne et al. estimation is nearest in timeline, it is based on Molecular Dynamics (MD) simulations and the calculated values are more distant if compared with the ideal behavior. An excellent correlation between the function reported by Chrenková and the one from Janz and Tomkins can also be observed; the standard deviation is 17.6 for the six plotted functions (Fig. 1b). Results of Cibulková et al. Eq.2 are close to Chrenková et al. Both of them are suggested as best currently values, giving a $0.38 \%$ deviation from average values. Any of this two functions may be extrapolated for the whole range $\mathrm{T} \in[933-1170]$ :

$$
\rho\left(\mathrm{kg} / \mathrm{m}^{\mathbf{3}}\right)=2579.3-0.6237 \cdot \mathrm{T}\left({ }^{\circ} \mathrm{K}\right)
$$

The usually suggested composition for ternary FLiNaBe in recent papers is $(0.31-0.31-0.38)$ or (0.33-0.33-0.33). The nearest correlation found was published by Williams et al. [60], by the method of additive molar volumes. Moreover, Beneš and Konings [80] suggested a different composition for the fuel matrix in MSR using $\mathrm{FLiNaBe}-\mathrm{AnF}_{4}$ (0.2030.571-0.212-0.013). Other researchers have proposed other expressions, e.g. Grimes et al. 32 for (0.35-0.27-0.38), Powers et al. 100] for (0.20-0.35$0.46)$, and Khokhlov et al. [106] for (0.22-0.5670.213 ) among others. All of them offer a similar slope (Fig.1c). The differences among the compositions result in a standard deviation value of 64.9 , but estimations like those of Williams et al. Eq. 3. are in halfway regarding the others (only $0.07 \%$ of deviation from the average) and are suggested for the temperature range $\mathrm{T} \in[800-1025]$ :

$$
\rho\left(\mathrm{kg} / \mathrm{m}^{3}\right)=2435.85-0.45 \cdot \mathrm{T}\left({ }^{\circ} \mathrm{K}\right)
$$

Two correlations have been found for NaFNaB, Cantor et al. [37] and 40]. Both equations are similar (Fig. 2a) giving 1.47 for standard deviation at the overlap interval, and results can be estimated by the second one for $\mathrm{T} \in[673-864]$ in order to obtain differences from the average minor than $0.06 \%$ :

$$
\rho\left(\mathrm{kg} / \mathrm{m}^{3}\right)=2446.2-0.711 \cdot \mathrm{T}\left({ }^{\circ} \mathrm{K}\right)
$$

FluZirK is being used recently in latest FHR concepts and proposals with (0.58-0.42) molar relation. For this salt, no correlations were made till 1988 to our best knowledge. Several data were formerly reported by Janz et al. [51] and then by Janz [57] at $1233.2{ }^{\circ} \mathrm{K}$. Different estimations were provided by Darienko et al. 107, 108, from 33 to $80 \mathrm{~mol} \%$ of $\mathrm{ZrF}_{4}$, and also an estimation may be calculated through the kinematic and dynamic viscosity relationship given in Darienko et al. [109]. The graphical analysis of the parameters given in the latter one shows an anomalous value for the $33 \mathrm{~mol} \% \mathrm{ZrF}_{4}$ compositions (whose standard deviation is higher, as for the 60 and $80 \mathrm{~mol} \%$ ). But, if we interpolate $\rho$ between 40 and $45 \%$ for the usual $42 \mathrm{~mol} \%$ the final curve fits with the others, which shows the accuracy in this molar concentration range. More recently a new correlation was published by Williams [61]. Studying the similarity among them (Fig. 2b), the slope is almost the same in all functions. Darienko et al. results are in a very good agreement in the three reported papers. However, the equation given by Williams is quantitatively far from the others. Indeed, standard deviation grows to 95.8 if taking into account Williams correlation, while deviation goes to 7.34 when calculating this value without this expression. When plotting all values together, proposals of Darienko et al. [108] (Eq.5) are more coherent to those initially published by Janz et al. and lately by Janz. The deviation from average is about $0.17 \%$ if we ignore Williams correlation; but this value raises to $1.7 \%$ if we use this expression for average estimation. Hence, although 

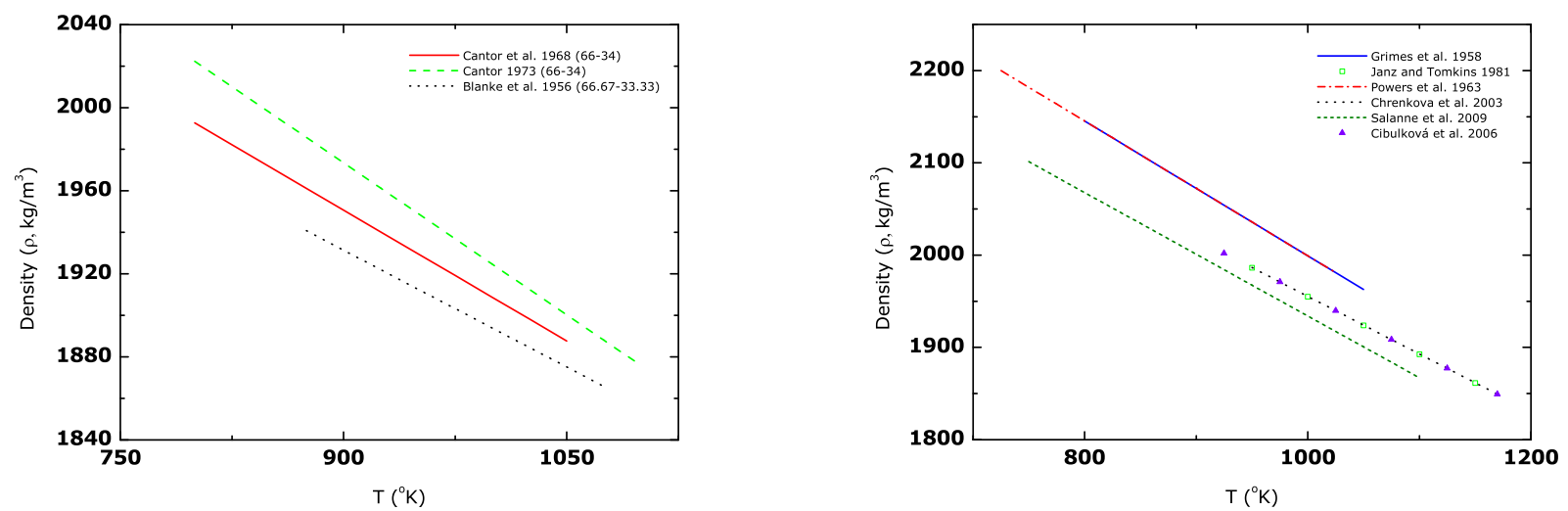

a FLiBe.

b FLiNaK.

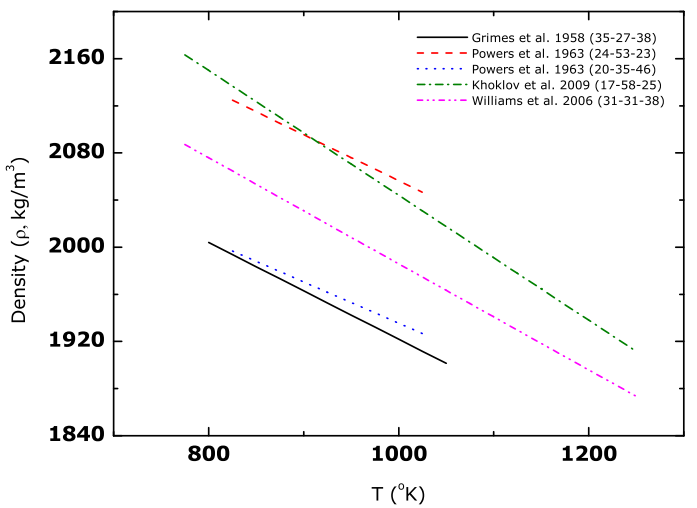

c FLiNaBe.

Fig. 1: Comparison of density variation with respect to temperature for the salts: FLiBe (a), FLiNaK (b), and FLiNaBe (c). Suggested values for each three salts are very near to average, giving a deviation below $0.9 \%$. 


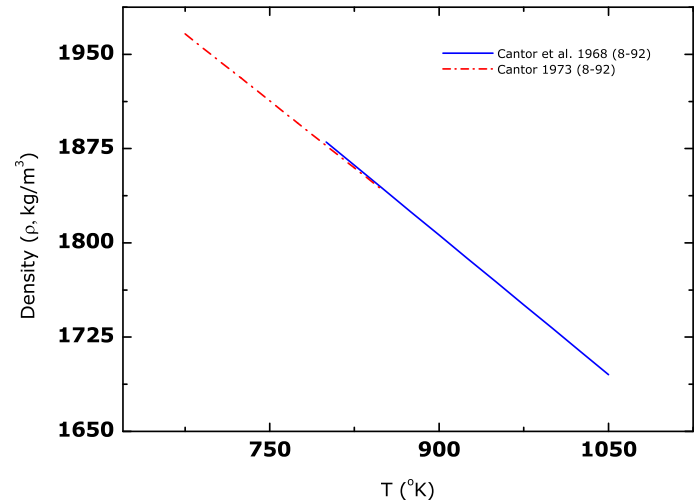

a $\mathrm{NaFNaB}$.

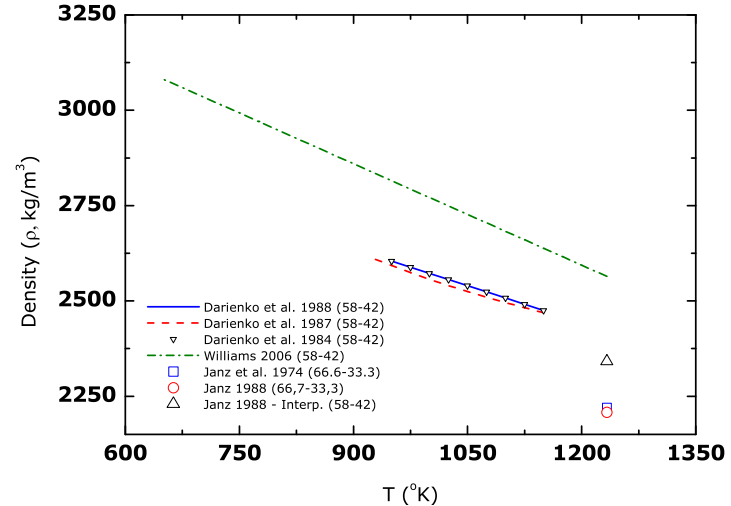

b FluZirK.

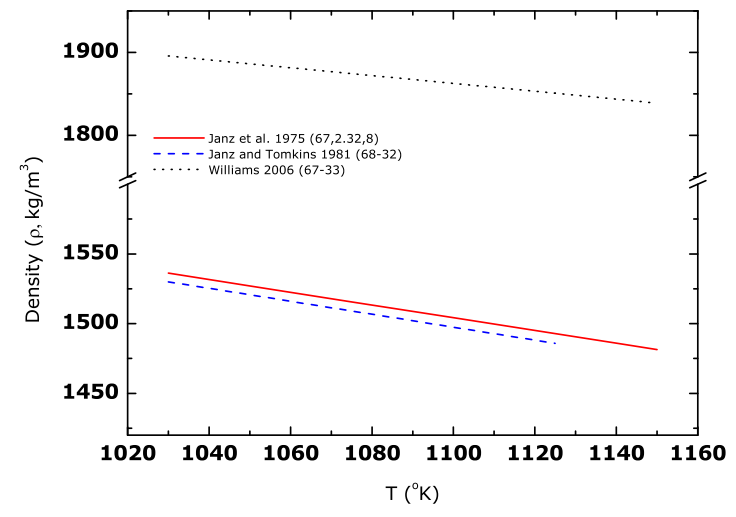

c CloKMag.

Fig. 2: Reviewed density correlations for $\mathrm{NaFNaB}$ (a), FluZirK (b) and CloKMag (c). A very good agreement is observed for $\mathrm{NaFNaB}$ (a). Plot for FluZirK (b) includes two different values correlated by Janz at $1233.2^{\circ} \mathrm{K}$ for the (0.67-0.33) molar ratio, and a extrapolated value for the (0.58-0.42) composition. Williams expressions give too high density values in the case of FluZirK and CloKMag mixtures, when compared with other measurements. 
Williams expression has been used in recent papers such as Anderson and Sabharwall [74], the most suitable correlation for the range $\mathrm{T} \in[953-1150]$ reads as follows:

$$
\rho\left(\mathrm{kg} / \mathrm{m}^{3}\right)=3217.44-0.6453 \cdot \mathrm{T}\left({ }^{\circ} \mathrm{K}\right)
$$

Classical works of Janz and Tomkins [49], Janz et al. 52] included several expressions to estimate the density for CloKMag, from 25 to $42.2 \mathrm{~mol} \%$ of $\mathrm{MgCl}_{2}$. Also Williams 62 has reported another expression, but values obtained with it are too far from the other ones (Fig. 2c). Standard deviation is about 4.64 if avoiding Williams correlation, while this value raises up to 221.6 when taking into account this expression. Hence, Janz et al. Eq. 6 is suggested for future works in the range $\mathrm{T} \in[1017-1174]$, with a $0.22 \%$ deviation from average (without Williams):

$$
\rho\left(\mathrm{kg} / \mathrm{m}^{3}\right)=2007-0.4571 \cdot \mathrm{T}\left({ }^{\circ} \mathrm{K}\right)
$$

Parameters for the so called Solar Salt (also known as draw salt) have been either published for the equimolar composition (near 1:1 molar ratio), and for the cheaper commercial mixture (0.64-0.36), or $60-40 \mathrm{wt} \%$. However, there are no significant differences in terms of density. This useful mixture was reported by Janz et al. 50] giving a second order equation in terms of temperature, and which allows to take into account the molar percentage of $\mathrm{KNO}_{3}$. Janz [57] includes linear expressions for the density from 30 to $50 \mathrm{~mol}_{\%}$ of $\mathrm{KNO}_{3}$. The eutectic composition of this salt was also studied by James and Liu 110], Carling et al. 111] and Nissen [112. Carling et al. reported two correlations, taking into account the thermal decomposition of nitrate to nitrite at extended time experiments. This maybe the reason of the second order proposal of Janz et al., but calculated values do not exactly agree in both cases. The correlation given by Nissen has been chosen by Zavoico [113] at Sandia National Laboratories, and is the current reference for the System Advisor Model (SAM) at the National Renewable Energy Laboratory (NREL). James and Liu values are slightly below from all the others, and the curve has also a different slope. For the two possibilities given by Carling et al., Nissen appears as the average value (Fig. 3a with $0.03 \%$ of deviation, and 13.10 as global standard deviation. As the values are so closer for the (0.64-0.36) commercial salt, negligible error is done by using the same correlation for both mixtures. The higher range of measurement reported by Nissen (Eq. 7) respect to Janz et al. suggests best accuracy. Therefore, for $\mathrm{T} \in[573-873]$ and the $(0.50-0.50)$ composition, the Nissen expression is as follows:

$$
\rho\left(\mathrm{kg} / \mathrm{m}^{3}\right)=2263.641-0.636 \cdot \mathrm{T}\left({ }^{\circ} \mathrm{K}\right)
$$

The last salt reviewed is the commercially denoted as Hitec ${ }^{\circledR}$, which has been largely used as HTF by chemical industry. Several studies can be mentioned, with very little differences (Fig. 3b among their mathematical expression and nearly the same after calculating values, e.g., Kirst et al. 114] (as cited by Gaune [115]), Janz and Tomkins 49], Yang and Garimella [116], Wu et al. 117] and Boerema et al. 118]. Additionally, values of SAM for the Hitec ${ }^{\circledR}$ composition [119] have been correlated (Eq.8). This last system is being commonly used as standard, giving a $0.09 \%$ deviation from the average. Using all the mentioned expressions, a value of 2.55 is calculated as standard deviation. Hence the recommended correlation for the temperature range $\mathrm{T} \in[448-773]$ reads:

$$
\rho\left(\mathrm{kg} / \mathrm{m}^{\mathbf{3}}\right)=2279.799-0.7324 \cdot \mathrm{T}\left({ }^{\circ} \mathrm{K}\right)
$$

Summarizing for density property, Table 2 shows the selected functions for each salt with the calculated percentage of deviation from the average values. Best fit is obtained for nitrates, followed by $\mathrm{NaFNaB}$ and FLiNaBe salts. Nevertheless, tabulated expressions provide acceptable estimations, even for FLiBe and FLiNaK (which show the higher scattering among reviewed data). A graphical sketch of selected functions is plotted in Fig. 4. This figure provides a quickly view for all the studied salts: FluZirK appears as the heaviest one, while CloKMag is the lightest of them. Molten salt density decreases as temperature increases in all the cases analyzed.

\subsection{Dynamic viscosity ( $\eta, P a \cdot s)$}

Most of selected salts follow an Arrhenius behavior in their temperature range. However, some nitrate salts are susceptible to decompose at high temperatures or extended time heat expositions. The non-Arrhenius behavior has been reported for some chloride mixtures by Boon et al. [120], discussed by Nissen [112] for equimolar Solar Salt, and 


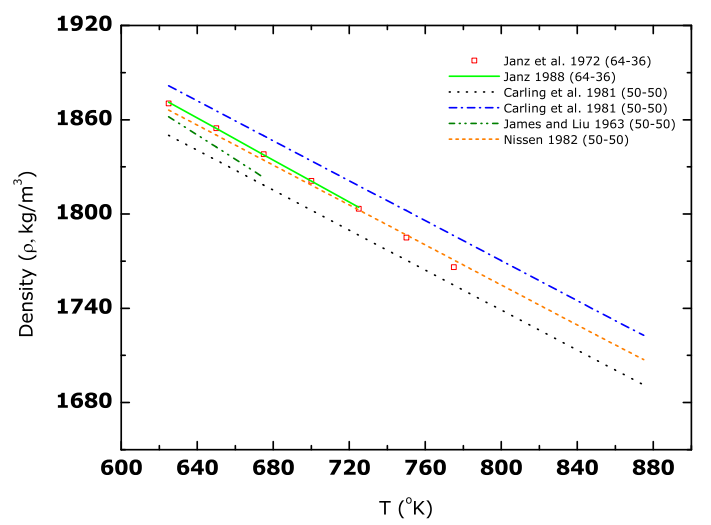

a Solar Salt.

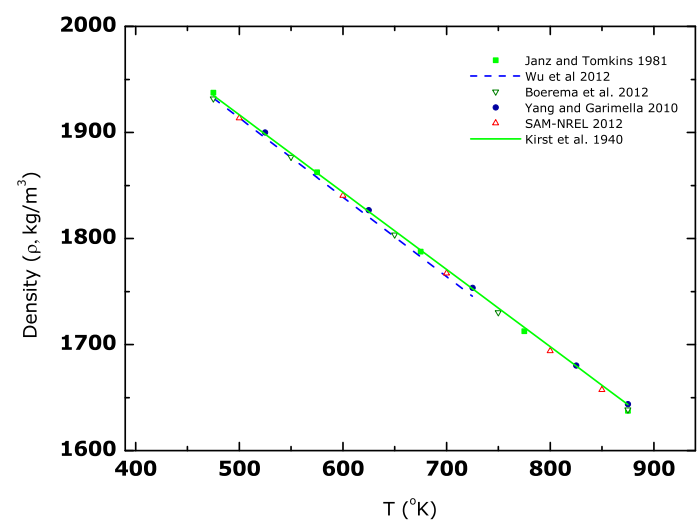

b Hitec ${ }^{\circledR}$.

Fig. 3: Density correlations for nitrates: Solar Salt (a), and Hitec ${ }^{\circledR}$ mixture (b).

Table 2:

Density correlations $\left(\mathrm{kg} / \mathrm{m}^{3}\right)$ as temperature function suggested for studied salts, including references and deviation from the global average data.

\begin{tabular}{|c|c|c|c|c|c|}
\hline Salt mixture & Reference & Ref. num. & Selected correlation & Temp. Range & \% Dev. \\
\hline FLiBe & Cantor 1973 (0.66-0.34) & 40 & $2413.03-0.4884 \cdot \mathrm{T}$ & [788-1094] & $0.89 \%$ \\
\hline FLiNaK & Chrenkova et al. $2003(0.465-0.115-0.42)$ & [102] & $2579.3-0.624 \cdot \mathrm{T}$ & [933-1170] & $0.38 \%$ \\
\hline FLiNaBe & Williams et al. 2006 (31-31-38) & 60 & $2435.85-0.45 \cdot \mathrm{T}$ & {$[800-1025]$} & $0.07 \%$ \\
\hline $\mathrm{NaFNaB}$ & Cantor 1973 (0.08-0.92) & 40] & $2446.2-0.711 \cdot \mathrm{T}$ & {$[673-864]$} & $0.06 \%$ \\
\hline FluZirK & Darienko et al. $1988(0.58-0.42)$ & 108 & $3217.44-0.6453 \cdot \mathrm{T}$ & [953-1150] & $0.17 \%$ \\
\hline CloKMag & Janz et al. 1975 (0.672-0.328) & 52 & $2007-0.4571 \cdot \mathrm{T}$ & [1017-1174] & $0.22 \%$ \\
\hline Solar Salt & Nissen $1982(0.50-0.50)$ & 112 & $2263.628-0.636 \cdot \mathrm{T}$ & {$[573-873]$} & $0.03 \%$ \\
\hline Hitec $^{\circledR}$ & SAM-NREL 2012 (0.07-0.49-0.44) & 119] & $2279.799-0.7324 \cdot \mathrm{T}$ & [448-773] & $0.09 \%$ \\
\hline
\end{tabular}




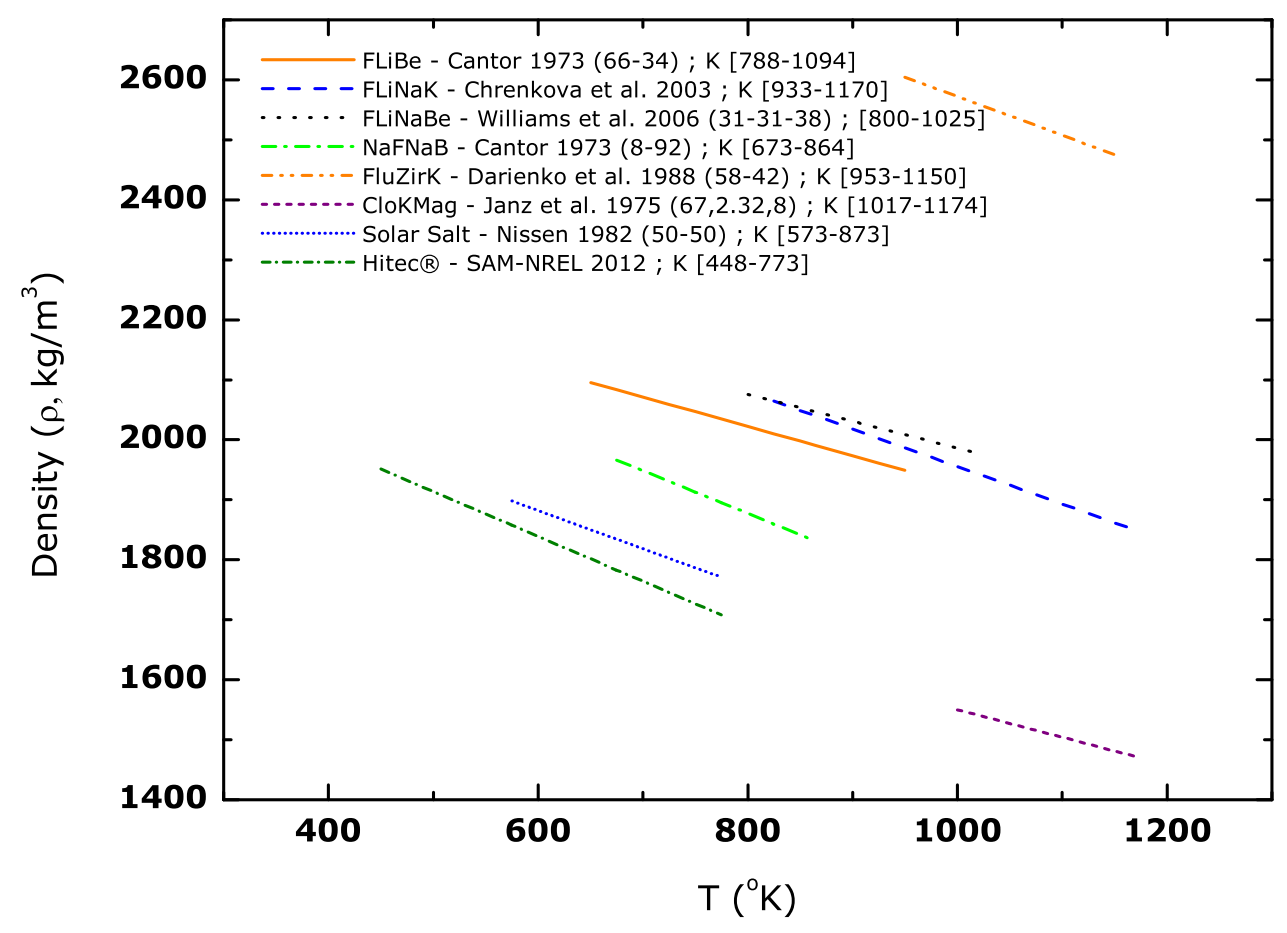

Fig. 4: Graphical density comparison of the different mixtures studied by selected correlations, showing a similar negative slope. 
lately described by Bradshaw 121 for some multicomponent nitrates. The Fulcher expression Eq.9 also known as VFTH) can be used for correlation in this cases, but several authors still use a simple polynomial regression.

$$
\log _{10}(\eta)=\mathrm{A}+\frac{\mathrm{B}}{\mathrm{T}-\mathrm{T}_{0}}
$$

Cantor et al. [39] also conjectured about the nonArrhenius behavior in FLiBe when applying low temperatures, which can be extrapolated for other molten salts. However, working range is higher to preclude this, far enough from the double of temperature of ideal glass transition point.

Around FLiBe viscosity, Salanne et al. [122] explained the reason of pure $\mathrm{BeF}_{2}$ high viscosity based in a $\mathrm{MD}$ study. $\mathrm{As} \mathrm{BeF}_{2}$ concentration increases in a FLiBe solution, different species are created, resulting in a polymer of several $\mathrm{BeF}_{4}^{2-}$ units at the highest percentages. Different investigations have been carried out about this physical property. Blanke et al. [33], Cantor et al. 37], Desyatnik et al. 123 measured viscosity for several molar concentrations of $\mathrm{BeF}_{2}$, while Cantor et al. 39], Cohen and Jones [95] and Abe et al. 98] studied only one mixture. Williams et al. 60] gave a correlation based on Cantor et al. 37], but the expression is one order of lower magnitude (Fig. 5a). The global standard deviation grows from 0.0004 to 0.0034 when including Williams expression. Janz et al. 51] and Janz and Tomkins [49] already used Cantor et al. correlations for the molten salt database.

Globally, the agreement is nearly perfect 88 among all values with the exception of Williams correlation, showing a rising curve when plotted all data in a $\mathrm{X}\left(\% \mathrm{BeF}_{2}\right), \mathrm{Y}(\log \eta)$ graph. For $\mathrm{T}>1050$, although viscosity becomes almost constant, data are near parallel (Fig.5a). Percentage of deviation from the average is around $4.97 \%$ for Cantor et al. and $\mathrm{T} \in[800-1050]$, and near to 7 $\%$ for Abe at al. at the same temperature interval. From these results, Abe et al. 98] is suggested for $\mathrm{T}>1050{ }^{\circ} \mathrm{K}$, while Cantor et al. [37] (Eq. 10 is selected for the range $\mathrm{T} \in[800-1050]$ :

$$
\eta(\mathrm{Pa} \cdot \mathrm{s})=0.000116 \cdot \exp \left(\frac{3755}{\mathrm{~T}\left({ }^{\circ} \mathrm{K}\right)}\right)
$$

Cohen and Jones 95] offered measurements for FLiNaK viscosity, later reported by Grimes et al. [32], Williams [62], Powers et al. [100], Korkut and
Hançerlioğulları 101]. Vriesema 97] used a different data (kinematic viscosity from a private communication of Oye, H. A.), and these values have been correlated using the same density of his heat transfer experiments. More recently, results provided by Chrenková et al. 102 and correlation listed by Janz and Tomkins [49] give nearly the same numbers (Fig. 5b), and both of them can be over-ranged by the equation of Cibulkova et al. [103] up to $1163^{\circ} \mathrm{K}$. After a comparison, and taking into account the discussed argument for FLiNaK density, we suggest the correlation of Cherenková et al. Eq. 11) for the range $\mathrm{T} \in[773-1163]$ (assuming negligible extrapolation error because of nearness to Cibulková et al. values). However, if using all reviewed data, the deviation from the average raises to a $9.87 \%$ due to the closeness of all values:

$$
\eta(\mathrm{Pa} \cdot \mathrm{s})=0.0000249 \cdot 10^{\left(\frac{1944}{\mathrm{~T}\left({ }^{\circ} \mathrm{K}\right)}\right)}
$$

The viscosity of FLiNaBe was measured by Cohen and Jones 95] for different compositions, then reported by Grimes et al. 32 for (0.35-0.27-0.38) molar mixture, and also correlations were given by Powers et al. 100 for some other compositions. Khokhlov et al. 106] made calculations using additive law of molar volumes of simple $\mathrm{LiF}$ and $\mathrm{BeF}_{2}$, with binary $\mathrm{LiF}-\mathrm{BeF}_{2}$ and $\mathrm{NaF}-\mathrm{BeF}_{2}$. As discussed by Zherebtsov and Ignatiév [67] the experimental data of early ORNL measurements are in good agreement with the more recent values. In addition, Ignatiév et al. 124 plotted a multicomparison graph showing a very good agreement with the Institute of High Temperature Electrochemistry (IHTE) modeling equations used in the International Science \& Technology Center (ISTC) \#1606-Project, when temperatures are over $600^{\circ} \mathrm{K}$. MSR application has been reviewed by Beneš and Konings 80 pointing to a recommended molar composition (0.22-0.5666-0.2133), but they reproduced the equation corresponding to (0.1433-0.59$0.2667)$ which must be taken into account. In other nuclear applications, the most referred promising mixture is near to the equimolar. To the author's knowledge, no investigation has been performed on this particular salt.

All reviewed correlations show a good agreement for temperatures higher to $950^{\circ} \mathrm{K}$ (Fig. 5c), where the composition dependence do not imply so much scattering. Therefore, searching for a global expression, accuracy of predictions for the range $\mathrm{T} \in[823-1023]$ is legitimated with the following 


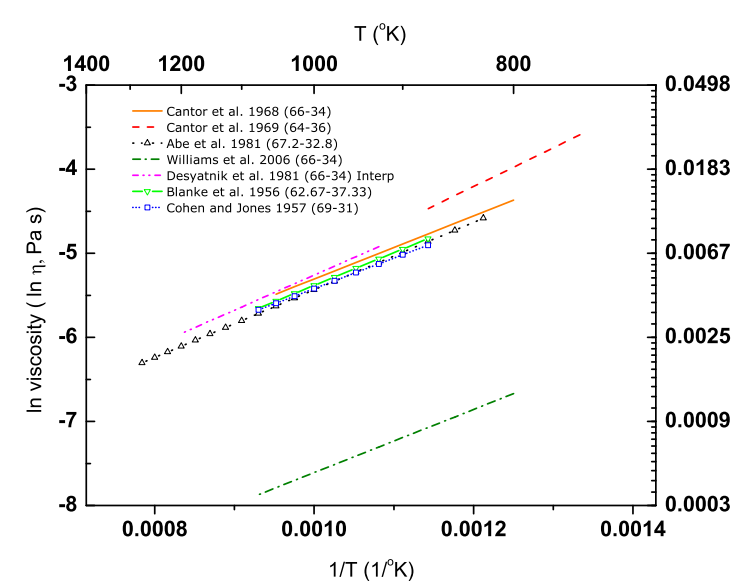

a FLiBe.

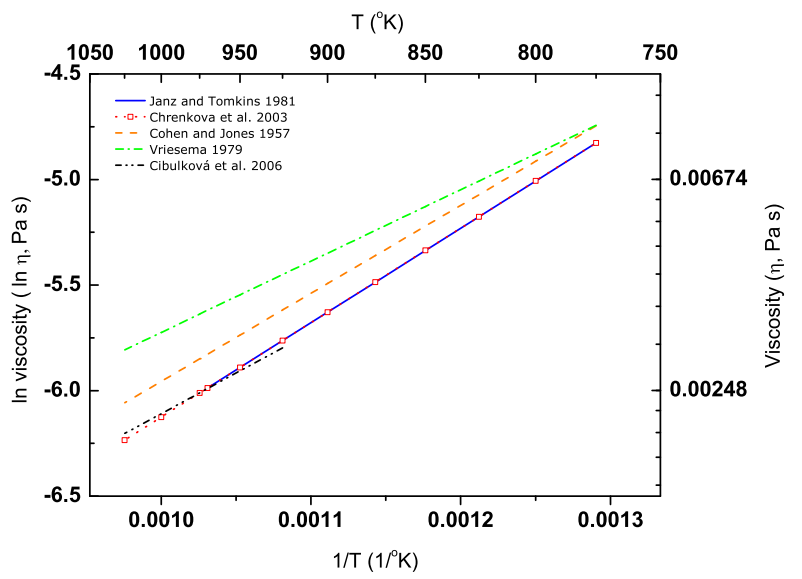

b FLiNaK.

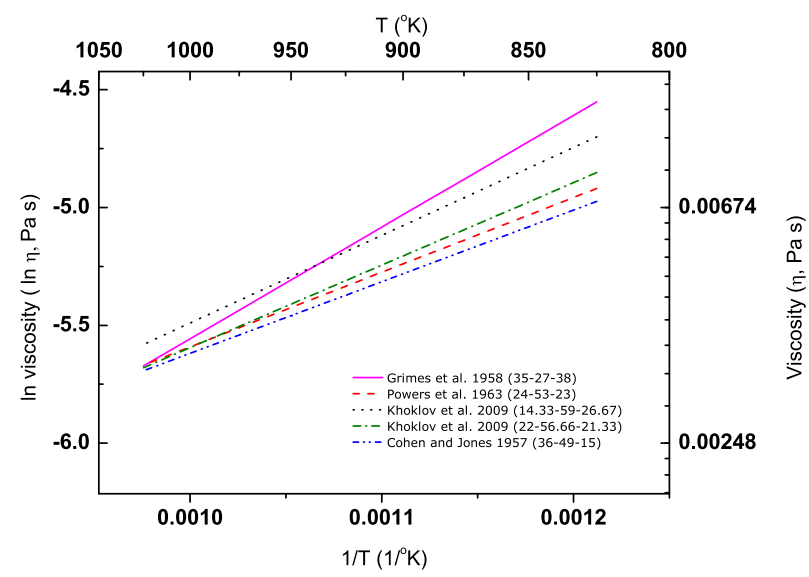

c FLiNaBe.

Fig. 5: Comparison of viscosity variation with respect to temperature for FLiBe (a), FLiNaK (b), and FLiNaBe (c), according to empirical correlations of different studies and authors. 
approach, which give a $12.35 \%$ of deviation from the overall average:

$$
\eta(\mathrm{Pa} \cdot \mathrm{s})=0.0000338 \cdot \exp \left(\frac{4738}{\mathrm{~T}\left({ }^{\circ} \mathrm{K}\right)}\right)
$$

Two formulations have been reported for $\mathrm{NaFNaB}$ at different temperature ranges. Cantor et al. 37] made a extrapolation for the behavior of sodium iodide based in experimental values for NaFNaB published by Wittenberg et al. 125 at Mound Laboratory. This latter correlation was defined for $\mathrm{T} \in[400-700]$. Thereafter Cantor [38] gave a new equation for the range $T \in[682-810]$, which has been subsequently cited in later reports as Cantor 40], Janz et al. 51], Janz 57]. Janz and Tomkins [56] expanded the temperature window between $799-906{ }^{\circ} \mathrm{K}$, but reviewing this reference there are no apparently reasons to include this new temperature range Fig. 6a. So we suggest the function reported by Cantor [38] but only for the range $\mathrm{T} \in[682-810]$. Reviewed data give 0.003 for standard deviation at the overlap interval, while suggested expression shows a $8.97 \%$ of deviation from average in the same interval:

$$
\eta(\mathrm{Pa} \cdot \mathrm{s})=0.0000877 \cdot \exp \left(\frac{2240}{\mathrm{~T}\left({ }^{\circ} \mathrm{K}\right)}\right)
$$

Janz et al. [51] proposed viscosity values for two compositions of FluZirK at $1253^{\circ} \mathrm{K}$. Later, Janz [57] reported an expression to calculate this property at the same temperature for a wide range of compositions, between $0-33,3 \mathrm{~mol} \%$ of $\mathrm{ZrF}_{4}$. More recently, Darienko et al. 109] measured FluZirK viscosity for concentrations from 0 to $80 \mathrm{~mol} \%$ of $\mathrm{ZrF}_{4}$, and Williams et al. [60] proposed a exponential correlation for the promising (0.58-0.42) composition as a function of temperature. Differences have been analyzed, after interpolating data from Darienko et al. for the same (0.58-0.42) mixture (Eq. 14). Expression reported by Williams et al. shows noticeably lower values the others, which means a 0.0022 global standard deviation and about $82.6 \%$ of deviance from the calculated average. However, our interpolation points to very similar values as previously listed by Janz and Janz et al. (Fig. 6b. Hence, although Williams correlation has been widely used and cited in many recent reports and papers (e.g., Beneš et al. 8], Williams 61], Samuel 66|, Anderson and Sabharwall 74], Kubíková et al. [126], Scheele and Casella [127], Sabharwall et al. [128, 129]), the following interpolated expression based in values of Darienko et al. is suggested in present work for the range $\mathrm{T} \in[921-1185]$, reducing deviation from the average to $45.24 \%$ when data of Williams are still included in calculations:

$$
\eta(\mathrm{Pa} \cdot \mathrm{s})=0.0001084 \cdot 10^{\left(\frac{1581.2}{\mathrm{~T}\left({ }^{\circ} \mathrm{K}\right)}\right)}
$$

The viscosity of binary chloride CloKMag was correlated for different molar concentrations by Janz et al. [52] and Janz and Tomkins [49], giving one third order polynomial expression (including the usually accepted 0.68-0.32 composition) and other standard Arrhenius formulation. Also Janz [57 and Williams 61 reported two different correlations for the mentioned (0.68-0.32) composition. By calculating values we have compared all the possibilities (Fig. 6c). Williams expression appears with a lower order of magnitude, giving a global $6.2 \cdot 10^{-4}$ standard deviation, while all the others are in good agreement. Standard deviation is reduced to $5 \cdot 10^{-5}$ when ignoring Williams correlation. Therefore, Janz [57] (Eq. 15) is the recommended correlation for the whole range $\mathrm{T} \in[900-1030]$, which means a $3.95 \%$ of deviation from the average:

$$
\eta(\mathrm{Pa} \cdot \mathrm{s})=0.0001408 \cdot \exp \left(\frac{2261.3}{\mathrm{~T}\left({ }^{\circ} \mathrm{K}\right)}\right)
$$

For the binary Solar Salt, negligible differences were found for viscosity between equimolar and commercial compositions. Initial measurements made by Murgulescu and Zuca were reported by Janz et al. [50] for the range $\mathrm{T} \in[525-725]$ after a critical review. These correlations included the $0,25,50,75$ and $100 \mathrm{~mol} \%$ of $\mathrm{NaNO}_{3}$, with Arrhenius form for the two first and a third order polynomial for the others. New Arrhenius expressions were reported by Janz [57] for the same molar composition cases, revising again the measurements mentioned above. For the equimolar salt, experimental data was given by Nissen [112], making a polynomial correlation used lately by Zavoico [113] for the Basis Document of the Solar Power Tower. Data offered in SAM NREL [119] have been also correlated, using polynomial (Eq.16) and Arrhenius forms. After a comparison, data chart of SAM give the same values as Nissen for a shorter temperature range (Fig. 7a). A value of $6 \mathrm{E}-05$ has been calculated as global standard deviation. Apparently, the equation given by Nissen shows the high temperature behavior of nitrates regarding to decomposition (as mentioned previously), while this 


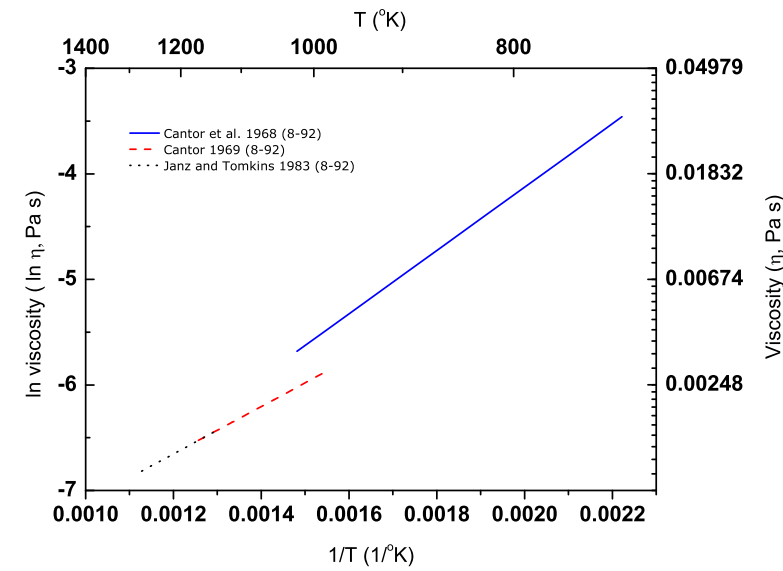

a $\mathrm{NaFNaB}$

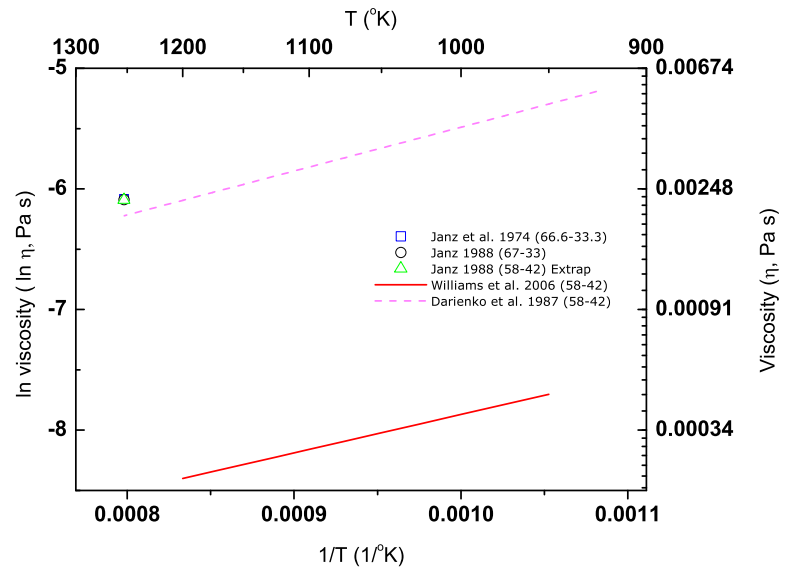

b FluZirK.

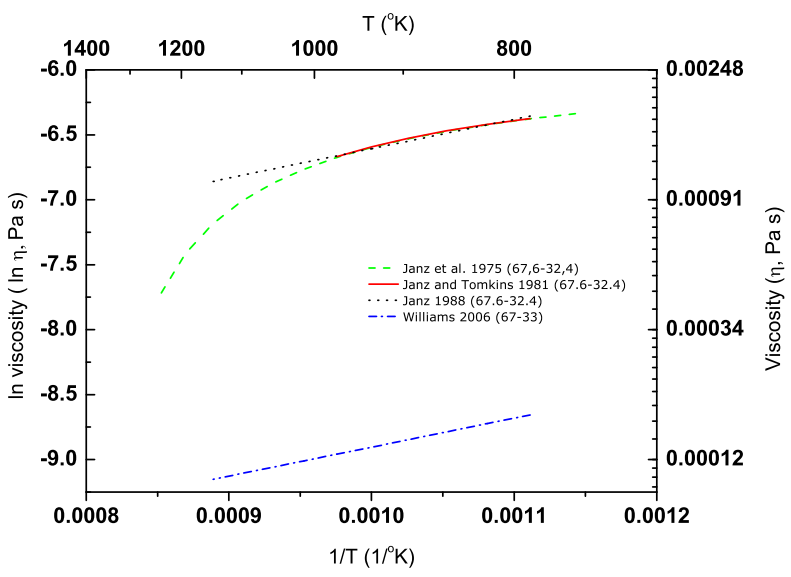

c CloKMag.

Fig. 6: Agreement among the reviewed correlations for NaFNaB viscosity (a). Graphical comparison (b) among different proposed functions and values correlated by Janz at $1253^{\circ} \mathrm{K}$ for FluZirK viscosity. Functions of temperature for CloKMag viscosity (c). The last two (b \& c) include the anomalous values obtained with the expressions reported by Williams. 


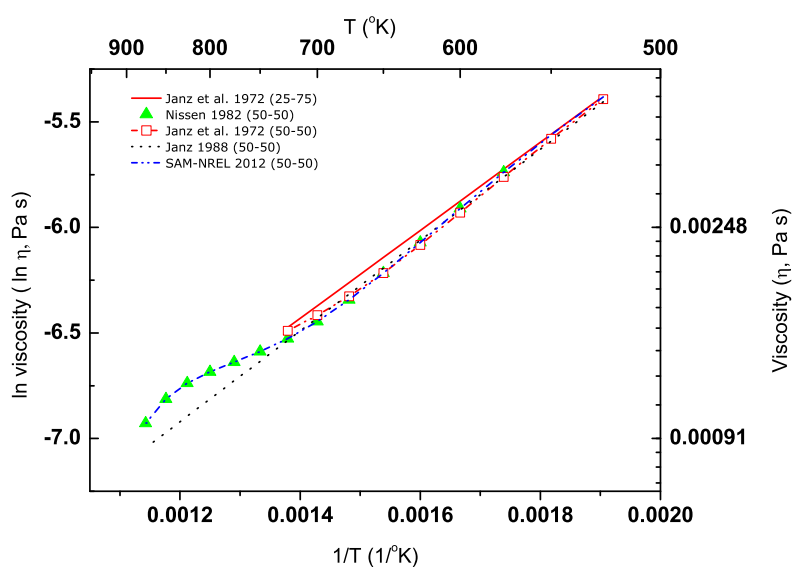

a Solar Salt.

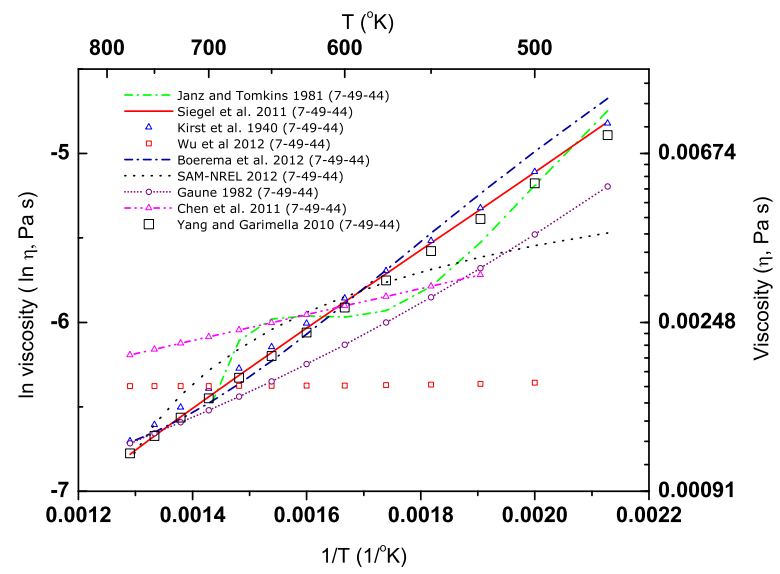

b Hitec ${ }^{\circledR}$.

Fig. 7: Graphical comparison of viscosity functions for Solar Salt (a) and Hitec (b).

chemical mechanism is not reflected in the Arrhenius form. In any case, the effect of molar composition is almost negligible. The following polynomial correlation is suggested for the whole range $\mathrm{T} \in[573-873]$, using data of Nissen, and giving a $2.33 \%$ of deviation from the average values:

$$
\begin{aligned}
& \eta(\mathrm{Pa} \cdot \mathrm{s})=0.07543937-2.77 \cdot 10^{-4} \cdot \mathrm{T}\left({ }^{\circ} \mathrm{K}\right) \\
& \quad+3.49 \cdot 10^{-7} \cdot \mathrm{T}^{2}\left({ }^{\circ} \mathrm{K}\right)-1.47 \cdot 10^{-10} \cdot \mathrm{T}^{3}\left({ }^{\circ} \mathrm{K}\right)
\end{aligned}
$$

Different correlations have been published for the Hitec ${ }^{\circledR}$ mixture. Kirst et al. [114] proposed a exponential behavior for temperatures between 473-773 ${ }^{\circ} \mathrm{K}$, while Gaune 115 used a second order func- tion of temperature for the same range, with Arrhenius global form. Janz and Tomkins [49] reported a third order polynomial correlation, but it shows a excessive slope at high temperatures regarding the others (probably due to thermal decomposition of nitrates). More recently, other authors have used other expressions, e.g. Yang and Garimella [116], Boerema et al. [118], Siegel et al. [130], Chen et al. [131] and Wu et al. [117]. Values of SAM NREL 119] have been also correlated to a linear expression in present work (Eq.17). After a comparison, Siegel et al. gives approximately the same values as Kirst et al. (Fig. 7b).

Boerema et al. gives the higher viscosity of all the correlations at low temperatures, as well as $\mathrm{Wu}$ et al. gives the lowest one, and shows a crescent function of temperature. The expression provided by Yang and Garimella is selected as the most representative. This correlation was obtained by correlating Coastal Chemical data, giving values in coherence with Solar Salt (also a nitrate mixture). Standard deviation is calculated, giving a global $3 \cdot 10^{-4}$ value. Hence, the suggested expresion for the range $\mathrm{T} \in[525-773]$, with $3.65 \%$ of deviation from the average, is as follows:

$$
\begin{gathered}
\eta(\mathrm{Pa} \cdot \mathrm{s})=\exp (-4.343-2.0143 . \\
\cdot\left(\left(\ln \left(\mathrm{T}\left({ }^{\circ} \mathrm{K}\right)-273\right)-5.011\right)\right)
\end{gathered}
$$

In short, for dynamic viscosity, suggested expressions are listed in Table 3 for all the studied mixtures. Data for Solar salt give the smallest deviation from average values, while correlations for NaFNab show the higher scattering by far (when compared with the other salts). A graphical comparison is plotted in Fig. 8 , all functions show a descent slope. Data for FLiBe are valid in a large temperature range, while viscosity correlations for the remainder mixtures are only useful for a short interval.

\subsection{Thermal conductivity $\left(\lambda, W \cdot \mathrm{m}^{-1} \cdot{ }^{\circ} \mathrm{K}^{-1}\right)$}

The measurement of thermal properties in molten salts has been pointed out by many authors as an arduous task, specially in the case of conductivity. At high temperatures, there are important uncertainties associated to the heat transfer mode. Nieto de Castro [132] also identified the combined effect of factors involved in this kind of measurement, analyzing the different methods available: (i) 
Table 3:

Viscosity correlations $(\mathrm{Pa} \cdot \mathrm{s})$ as temperature function, including final deviation from the average values after ignoring both too high as too low values.

\begin{tabular}{|c|c|c|c|c|c|}
\hline Salt mixture & Reference & Ref. Num. & Selected correlation & Temp. Range & \% Dev. \\
\hline FLiBe & Cantor et al. 1968 (0.66-0.34) & [37] & $1.16 \cdot 10^{-4} \cdot \exp (3755 / \mathrm{T})$ & [800-1050] & $4.97 \%$ \\
\hline FLiNaK & Chrenkova et al. $2003(0.465-0.115-0.42)$ & 102 & $2.49 \cdot 10^{-5} \cdot 10^{\wedge}(1944 / \mathrm{T})$ & [773-1163] & $9.87 \%$ \\
\hline FLiNaBe & Grimes et al. $1958(0.35-0.27-0.38)$ & 32] & $3.38 \cdot 10^{-5} \cdot \exp (4738 / \mathrm{T})$ & [823-1023] & $12.35 \%$ \\
\hline $\mathrm{NaFNaB}$ & Cantor 1969 (0.08-0.92) & 38 & $8.77 \cdot 10^{-5} \cdot \exp (2240 / \mathrm{T})$ & {$[682-810]$} & $8.97 \%$ \\
\hline FluZirK & Darienko et al. $1987(0.58-0.42)$ & 109 & $1.084 \cdot 10^{-4} \cdot 10^{\wedge}(1581.2 / \mathrm{T})$ & {$[921-1185]$} & $45.24 \%$ \\
\hline CloKMag & Janz 1988 (0.676-0.324) & 57 & $1.408 \cdot 10^{-4} \cdot \exp (2261.3 / \mathrm{T})$ & [900-1030] & $3.95 \%$ \\
\hline Solar Salt & Nissen $1982(0.50-0.50)$ & 112 & $\begin{array}{c}0.075439-2.77 \cdot 10^{-4} \cdot(\mathrm{T}-273) \\
+3.49 \cdot 10^{-7} \cdot(\mathrm{T}-273)^{2} \\
-1.474 \cdot 10^{-10} \cdot(\mathrm{T}-273)^{3}\end{array}$ & {$[573-873]$} & $2.33 \%$ \\
\hline Hitec $^{\circledR}$ & Yang and Garimella 2010 (0.07-0.49-0.44) & {$[116$} & $\exp (-4.343-2.0143 \cdot(\ln (\mathrm{T}-273)-5.011))$ & {$[525-773]$} & $3.65 \%$ \\
\hline
\end{tabular}

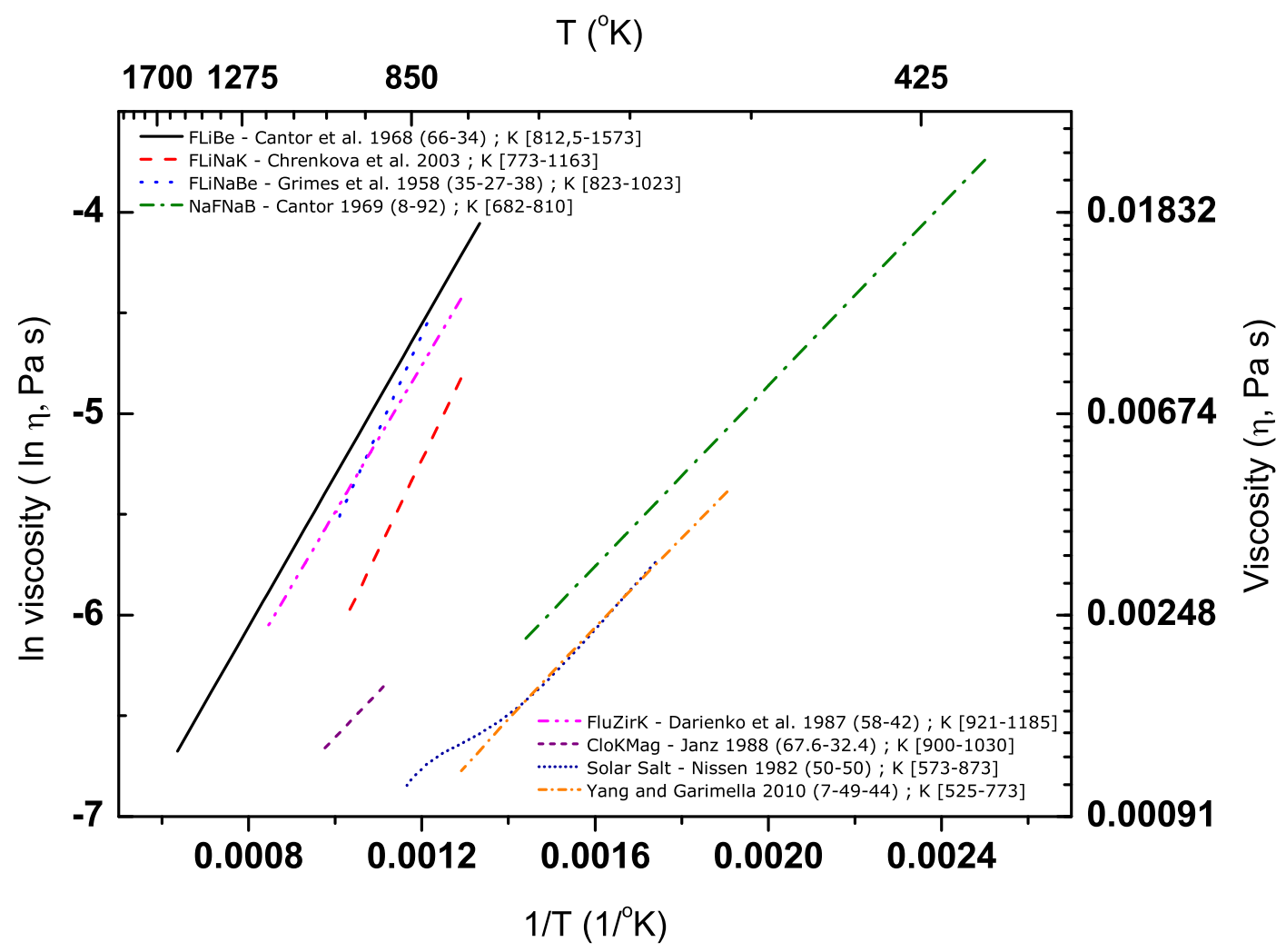

Fig. 8: Global plot of selected expressions of viscosity for the different mixtures studied. A descent slope is showed by all the salts. The lowest viscosity values, in studied temperature intervals, correspond to nitrates and chlorides. 
the sample purity and homogeneity, (ii) thermal stability of salt, (iii) interaction between the sample and both the surrounding gaseous atmosphere and the container material, (iv) temperature measurement sensor, and ( $\mathrm{v}$ ) other simultaneous heat transfer mechanisms such as convection and radiation. Some interesting thought was exposed by Nunes et al. [14], in order not to design under or overdimensioned heat exchangers or industrial equipments. DiGuilio and Teja 133] discussed about the influence of electrical charges, the pressure dependence, the presence of a saturation curve, and the effect of size of ions in salt families. The method of measurement is also a key issue for molten salts. This circumstance was also argued by Diguilio and Teja and by Nieto de Castro, advising about examples of positive or negative slope for the same salt by different authors. In fact, Diguilio and Teja reported erroneous slope values for some nitrates and chlorides.

Among correlation methods, many formulations have been developed and reported with different assumptions, e.g., Bridgman and KindcaidEyring equation [134], Mean-ionic-weight and RaoTurnbull correlations [135], and Gustafsson and Rough-Hard-Sphere models 133. Khokhlov et al. [106] proposed a standard function of temperature and molecular weight for multicomponent fluorides. In order to check its behavior, some correlations have been extended for all the selected salts in the present work.

Both experimental or estimated data have been found in the literature for the selected salt mixtures. After a global comparison, a low temperature dependence is showed (Fig. 9]. Rao-Turnbull [136, 137. prediction shows acceptable values for melting point, but is very sensitive to the average number of ions per mole (a proposal of ions is listed in Cooke et al. 134 for different mixtures). The assumptions for this correlation made by Williams et al. 60] have been recalculated, obtaining different values other than in this work. Khokhlov et al. 106 functions appears always with a positive slope, which is not true for some mixtures, and the calculated values seem to be only coherent with measurements for fluorides and chlorides (but not with fluoborates or nitrates).

For FLiBe, we have plotted results and proposals from Cantor et al. 37], Williams et al. [60], Cooke et al. 134, 138], Kato et al. 139] and Khokhlov et al. [106], and recalculated Rao-Turnbull correlation. As the temperature dependence is relatively low, we agree with Beneš and Konings [80] recommending $\lambda=1.1 \mathrm{~W} \cdot \mathrm{m}^{-1} \cdot{ }^{\circ} \mathrm{K}^{-1}$, with a $0.29 \%$ deviation from the average value.

FLiNaK investigations show a wide rage of data from 0.6 to $4.5 \mathrm{~W} \cdot \mathrm{m}^{-1} \cdot{ }^{\circ} \mathrm{K}^{-1}$. The Rao-Turnbull value moves from 0.7 to 1.58 when the number of ions is changed between 1 or 2. Several measurements and estimations have been compared: Grele and Gedeon [20], Hoffman and Lones [21], Grimes et al. 32], Janz and Tomkins [49], Vriesema [97], Powers et al. [100], Kato et al. [139], Ewing et al. 140], Smirnov et al. 141] and Khokhlov et al. 106]. Kato et al. values are derived from thermal diffusivity data. Ewing et al. showed decreasing transmission coefficients, which was explained due to solution of container components.

For the usual composition Beneš and Konings 80. conclusions recommended a linear equation with positive slope. However, DiGuilio and Teja 133 discussed this behavior for the alkali halides (descent slope). In any case, there is good agreement among Kato et al. [139] and Smirnov et al. 141. Therefore, a constant value of $\lambda=0.85 \mathrm{~W} \cdot \mathrm{m}^{-1} \cdot{ }^{\circ} \mathrm{K}^{-1}$ is suggested in agreement with this two last authors and the expression of Khokhlov et al. 106. The standard deviation is too high if values of Grele and Gedeon [20], Hoffman and Lones 21], Grimes et al. 32], Powers et al. [100] and Janz and Tomkins [49] are used in calculations, growing up to 1.29; but it decreases till 0.21 when this anomalous values are ignored. Using all data to compute the average the deviation of suggested value is about $51.29 \%$, but it only $10.78 \%$ when anomalous values are not taken into account.

There are few estimations for FLiNaBe mixture, and most of them are for different compositions. Grimes 35, 142], Ignatiév et al. [143] and Khokhlov et al. 106 have been revised in the present work. Because of the lack of experimental data, a constant value of $\lambda=0.70 \mathrm{~W} \cdot \mathrm{m}^{-1} \cdot{ }^{\circ} \mathrm{K}^{-1}$ is selected for the (0.31-0.31-0.28) mixture, which is coherent with Rao-Turnbull correlation with $\mathrm{n}=1$. The deviation from average is around $18.21 \%$ for the suggested heat capacity.

Several values have been published for $\mathrm{NaFNaB}$ with (0.08-0.92) molar composition, such as Cantor et al. [37, Cooke et al. 134, 138], Grimes 142] and Khokhlov et al. [106]. Analyzing the proposed functions, thermal conductivity can be evaluated by Rao-Turnbull equation $(n=2)$, giving $\lambda=0.47 \mathrm{~W} \cdot \mathrm{m}^{-1} \cdot{ }^{\circ} \mathrm{K}^{-1}$ with $0.44 \%$ of deviation from average. 
To our best knowledge, no measurements about FluZirK have been published. A standard value, for (0.58-0.42) molar composition, can be estimated in coherence with Rao-Turnbull expression $(\mathrm{n}=1)$ and Khokhlov et al. correlation. Hence $\lambda=0.30 \mathrm{~W} \cdot \mathrm{m}^{-1} \cdot{ }^{\circ} \mathrm{K}^{-1}$ is found to be a good constant value (19.61\% of deviation from the average).

The thermal conductivity of CloKMag have been reported by Janz and Tomkins [49] for the (0.66-0.34) and (0.71-0.29) molar compositions. Williams et al. 60 calculated a value of 0.39 $\mathrm{W} \cdot \mathrm{m}^{-1} \cdot{ }^{\circ} \mathrm{K}^{-1}$ by simple mole-fraction average of the pure-compound data, which has been recently suggested by Anderson and Sabharwall [74]. By using again the Rao-Turnbull estimation $(\mathrm{n}=2, \mathrm{n}=1$, and $n=1.5)$, the values obtained are $0.55,0.25$ and $0.40 \mathrm{~W} \cdot \mathrm{m}^{-1} \cdot{ }^{\circ} \mathrm{K}^{-1}$ respectively. The estimation function of Khokhlov et al. 106 is near parallel to data obtained by Janz and Tomkins [49] correlation, and agrees with Rao-Turnbull $(\mathrm{n}=1.5)$ and Williams et al. calculations. Therefore, a constant value for thermal conductivity of $\lambda=0.55 \mathrm{~W} \cdot \mathrm{m}^{-1} \cdot{ }^{\circ} \mathrm{K}^{-1}$ is suggested with temperature independence, in coherence with Rao-Turnbull estimation for $\mathrm{n}=2$. Deviation from average is about $14.02 \%$, and 0.16 is the computed standard deviation.

The scattering of data is even larger for nitrate compositions, as they have been studied extensively. Thermal decomposition of this kind of salts must be taken also into account, which can be significantly enhanced by controlling the atmosphere, as recently discussed by Olivares [144]. Several reports for Solar Salt (with different molar compositions) have been reviewed, and also the SAM data have been correlated by linear regression: Janz et al. [48], McDonald and H. Ted Davis [145], Omotani et al. [146], Tufeu et al. 147] and Zavoico 113. According to DiGuilio and Teja [133], temperature dependence must show negative slope. This feature is only followed by Omotani et al. and Tufeu et al. expressions. Khokhlov et al. 106 function does not match the measured values. In general, correlated values give a maximum of 0.58 and a minimum of $0.42 \mathrm{~W} \cdot \mathrm{m}^{-1} \cdot{ }^{\circ} \mathrm{K}^{-1}$ for the range $\mathrm{T} \in[600-730]$, and Rao-Turnbull gives $0.47 \mathrm{~W} \cdot \mathrm{m}^{-1} \cdot{ }^{\circ} \mathrm{K}^{-1}$. The latter value agrees with Tufeu et al. and Omotani et al. correlations, and DiGuilio and Teja [133] predictions. Hence, a constant $\lambda=0.45 \mathrm{~W} \cdot \mathrm{m}^{-1} \cdot{ }^{\circ} \mathrm{K}^{-1}$ is found to be a good choice, showing a $10.12 \%$ of deviation from average.

Finally, Hitec ${ }^{\circledR}$ correlations have been reviewed.
SAM database has been also accessed, in order to compare values with Janz and Tomkins [49], Yang and Garimella [16], Wu et al. [117], Cooke et al. 134|, Tufeu et al. 147], Omotani and Nagashima 148], Santini et al. [149 and Boerema et al. 118. The plotted functions of temperature show a dispersion around an average value, which is close to Rao-Turnbull estimation for $\mathrm{n}=2$ and giving $\lambda=0.48 \mathrm{~W} \cdot \mathrm{m}^{-1} \cdot{ }^{\circ} \mathrm{K}^{-1}$. The latter is also very close to Tufeu et al. and Omotani et al. values. The global standard deviation for this property and salt has been computed about 0.097. Although there is a general disagreement among most recent reports, a suggested value of $\lambda=0.48 \mathrm{~W} \cdot \mathrm{m}^{-1} \cdot{ }^{\circ} \mathrm{K}^{-1}$ is also in coherence with DiGuilio and Teja 133. arguments for $\mathrm{KNO}_{3}$ and nitrate mixtures. The deviation from average for this last value is calculated to be around $4.36 \%$.

Trying to make a brief summary for this property, Fig. 9 shows a global view of reviewed values for thermal conductivity and all studied salts. Although most of mixtures shows a high scattering when studied separately, some conclusions can be made with a general overview. For example, most of data are bounded into the range $0.25-1.30 \mathrm{~W} \cdot \mathrm{m}^{-1} \cdot{ }^{\circ} \mathrm{K}^{-1}$. In case of nitratenitrite salts, this interval can be reduced to $0.25-0.70 \mathrm{~W} \cdot \mathrm{m}^{-1} \cdot{ }^{\circ} \mathrm{K}^{-1}$, with independence of temperature value. For fluorides, data are bounded into $0.25-1.30 \mathrm{~W} \cdot \mathrm{m}^{-1} \cdot{ }^{\circ} \mathrm{K}^{-1}$ if anomalous values reported by Grele and Gedeon 20], Hoffman and Lones [21] and Janz and Tomkins [49] for FLiNaK are ignored. In general, more tests are needed so as to asses better or newer correlations for salts at high temperature conditions. Hence, with currently knowledge, a constant value may be a good option to get acceptable accuracy in calculations (Table 4).

\subsection{Heat capacity ( $\left.\mathrm{Cp}, J \cdot \mathrm{kg}^{-1} \cdot \mathrm{K}^{-1}\right)$}

Khokhlov et al. 106 reported a general correlation for multi-component fluorides. In order to asses further possibilities, this expression have been made extensive to the other molten salts in this work. Some other functions of temperature have been found for certain salts as plotted in Fig. 10. Cantor 36] proposed the assumption of temperature independence for this property, because of the small accuracy observed in experiments. Cantor modified the Dulong-Petit expression for molten fluorides, using an average value for heat capacity 


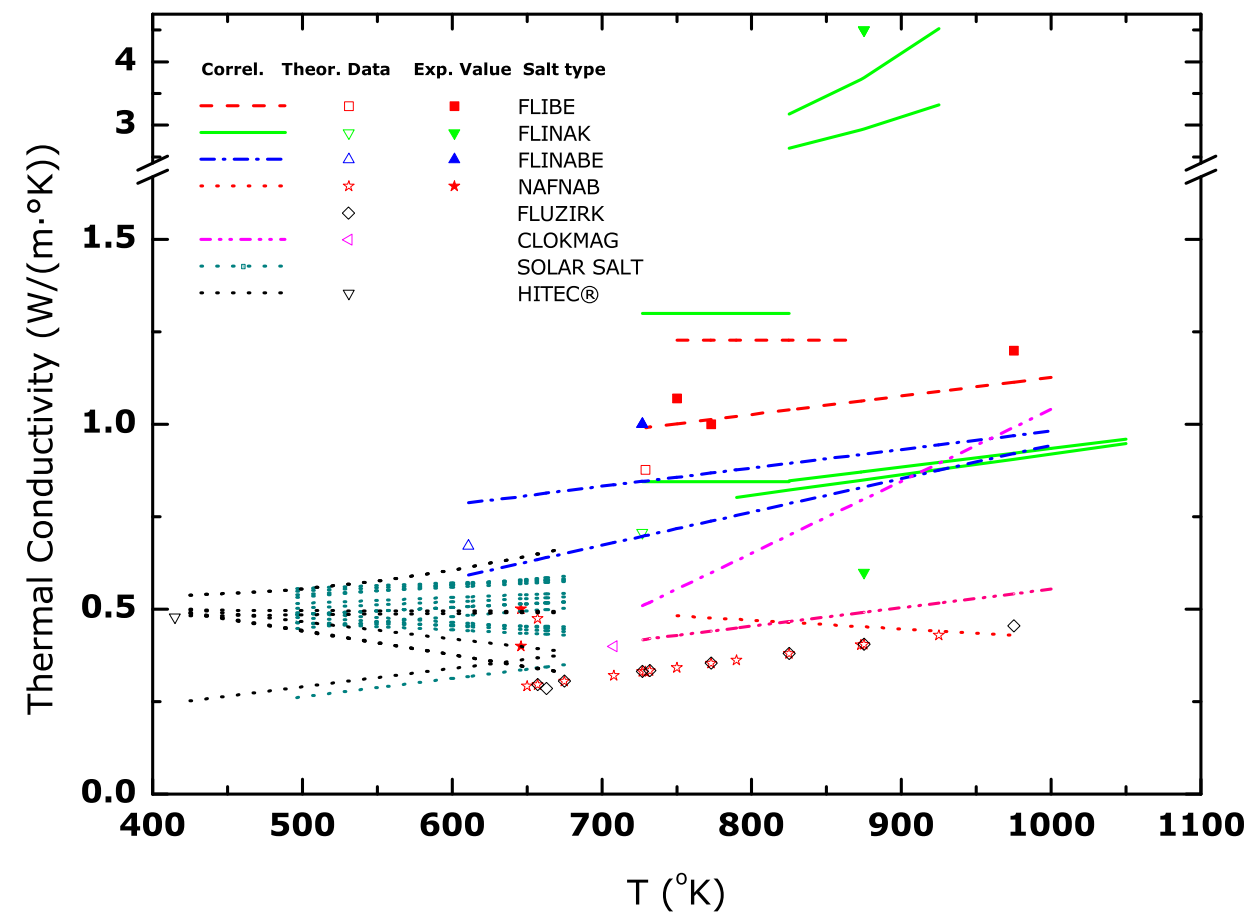

Fig. 9: Graph summarizing the thermal conductivity correlations and estimated values proposed by different authors at different temperatures. Legend inside the graph shows: Lines defining different correlations reported for each kind of salt; Symbols representing point values for theoretical estimations (open symbols), or reported experimental measurements (filled symbols). 


\section{Table 4:}

Summary of suggested constant values for thermal conductivity $\left(\lambda, \mathrm{W} \cdot \mathrm{m}^{-1} \cdot{ }^{\circ} \mathrm{K}^{-1}\right)$, with temperature independence. Table include the calculated standard deviation for studied data, and $\%$ of deviation of selected values from the average. Deviation from average for FLiNaK is too high if anomalous high values are not avoided in calculations (51.29 $\%$ ), but decrease to $10.78 \%$ when this values are not used.

\begin{tabular}{cccc}
\hline Salt mixture & Constant value & Stand. Dev. & $\%$ Dev. \\
\hline \hline FLiBe & 1.10 & 0.096 & $0.29 \%$ \\
\hline FLiNaK & 0.85 & 0.206 & $10.78 \%$ \\
\hline FLiNaBe & 0.70 & 0.105 & $18.21 \%$ \\
\hline NaFNaB & 0.47 & 0.016 & $0.44 \%$ \\
\hline FluZirK & 0.30 & 0.054 & $19.61 \%$ \\
\hline CloKMag & 0.55 & 0.163 & $14.02 \%$ \\
\hline Solar Salt & 0.45 & 0.067 & $10.12 \%$ \\
\hline Hitec ${ }^{\circledR}$ & 0.48 & 0.097 & $4.36 \%$ \\
\hline
\end{tabular}

per atom $\left(33.472 \mathrm{~J} /{ }^{\circ} \mathrm{K}\right)$. This proposal was used by Williams et al. [60], making a comparison with measurements at $973{ }^{\circ} \mathrm{K}$. A global graph is showed in Fig. 11, including reported and estimated values. The suggested values for each salt are summarized in Table 5

For FLiBe, values were reported by Grimes et al. [32] for (0.69-0.31) and (0.50-0.50) compositions at $973^{\circ} \mathrm{K}$. Cantor et al. 37] (from an internal report of Hoffman and Lones) and Douglas and Payne [150] also gave values for the promising (0.66-0.34) mixture. Heat capacity of FLiBe can be also obtained of Kato et al. [139] from thermal diffusivity. By comparison, we propose Cantor et al. 37] as a constant value, giving $C p=2385 \mathrm{~J} \cdot \mathrm{kg}^{-1} \cdot{ }^{\circ} \mathrm{K}^{-1}$ and a $5.26 \%$ of deviation from the average.

First found data for FLiNaK were published by Poppendick [22], and also by Powers and Blalock at ORNL 151] using a Bunsen calorimeter. Grele and Gedeon [20] used $2092 \mathrm{~J} \cdot \mathrm{kg}^{-1} \cdot{ }^{\circ} \mathrm{K}^{-1}$ with temperature independence, based on data reported by Poppendick. Other proposals were made by Janz and Tomkins [49], Kato et al. [139] and Salanne et al. 104] (this last, from a first-principles deter-

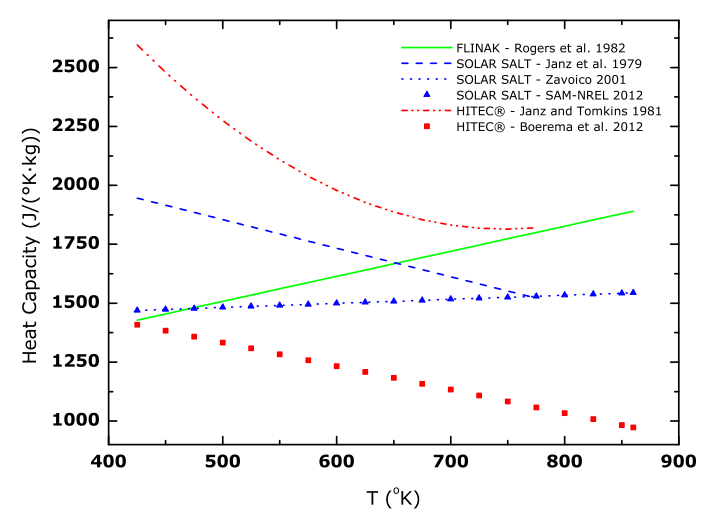

Fig. 10: Correlations found for heat capacity in the case of FLiNaK $(-)$, Solar Salt $(-\ldots, \ldots, \mathbf{\Delta})$ and $\operatorname{Hitec}^{\circledR}\left({ }^{\circledR} \cdot-, \mathbf{m}\right)$ mixtures and usual compositions.

mination). Kato et al. values are based on thermal diffusivity data. Vriesema 97 used a constant value of $1890 \mathrm{~J} \cdot \mathrm{kg}^{-1} \cdot{ }^{\circ} \mathrm{K}^{-1}$. Rogers et al. [152] also reported a correlation for this property with positive slope, as showed in Fig. 10. Published data are higher than ideal behavior in agreement with Beneš and Konings [80]. After verifying the strong correlation among the constant reported data (standard deviation of 208.46), a heat capacity of $C p=1880 \mathrm{~J} \cdot \mathrm{kg}^{-1} \cdot{ }^{\circ} \mathrm{K}^{-1}$ is suggested to be a good value with $6.07 \%$ of deviation from average.

For the molten FLiNaBe, several values have been reported for different molar compositions. However, none of them for the equimolar or (0.310.31-0.38) compositions. Grimes et al. 32 gave $2467 \mathrm{~J} \cdot \mathrm{kg}^{-1} \cdot{ }^{\circ} \mathrm{K}^{-1}$ value for $(0.35-0.27-0.38)$ at $973^{\circ} \mathrm{K}$, and Powers et al. 100 reviewed for different molar percentages at the same temperature, as well as Grimes [35] at $727^{\circ} \mathrm{K}$. A global standard deviation of 158.15 has been calculated for reviewed data. For the selected composition (0.31$0.31-0.38)$, we suggest a constant heat capacity of $C p=2200 \mathrm{~J} \cdot \mathrm{kg}^{-1} \cdot{ }^{\circ} \mathrm{K}^{-1}$ which has a $0.48 \%$ of deviation from average.

No measurements have been found for FluZirK. Only estimated values can be obtained by the mentioned Khokhlov et al. 106 and Cantor-DulongPetit correlations. A constant heat capacity of $C p=1000 \mathrm{~J} \cdot \mathrm{kg}^{-1} \cdot{ }^{\circ} \mathrm{K}^{-1}$ is prudently proposed with $5.36 \%$ of deviation from the average of estimations.

Only two references have been found for $\mathrm{NaFNaB}$ 


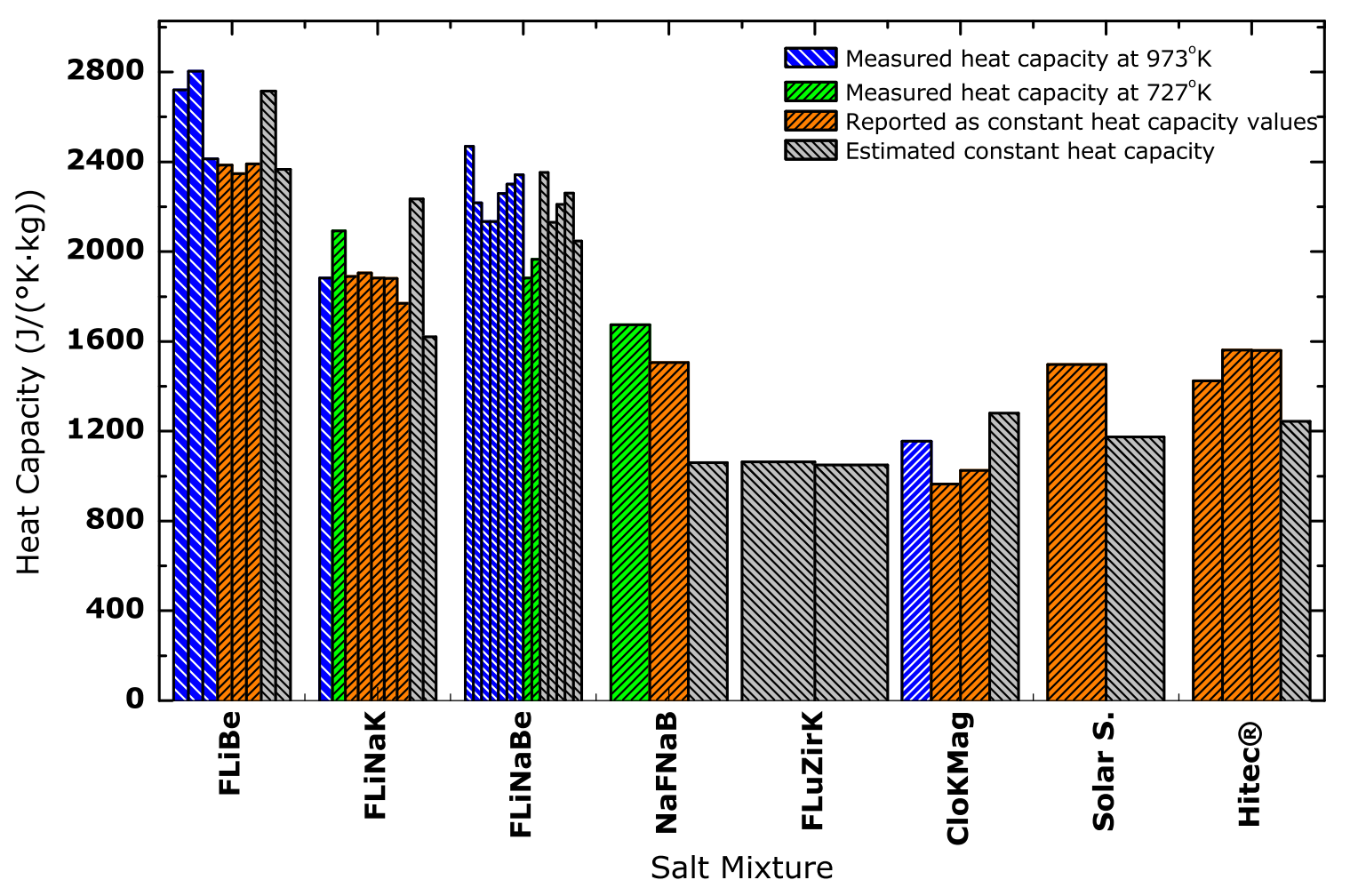

Fig. 11: Global comparison of reported values of heat capacity for selected salts and different compositions. 
(0.08-0.92). Grimes 35 reported a value of $1674 \mathrm{~J} \cdot \mathrm{kg}^{-1} \cdot{ }^{\circ} \mathrm{K}^{-1}$, and as mentioned in Cantor et al. [37], Dworkin measured it giving $C p=1506 \mathrm{~J} \cdot \mathrm{kg}^{-1} \cdot{ }^{\circ} \mathrm{K}^{-1}$, which is the suggested value for this salt. Calculated deviation from the average is about $6.56 \%$ in this case.

For CloKMag (0.666-0.334) and (0.418-0.582) compositions, Janz and Tomkins [49] reported 964 and $1026 \mathrm{~J} \cdot \mathrm{kg}^{-1} \cdot{ }^{\circ} \mathrm{K}^{-1}$ respectively. Williams [61] also reported a measured value at $973{ }^{\circ} \mathrm{K}$ of $C p=1155 \mathrm{~J} \cdot \mathrm{kg}^{-1} \cdot{ }^{\circ} \mathrm{K}^{-1}$ for the mixture $(0.67$ $0.33)$, which is suggested as good value $(4.42 \%$ of deviation from average).

The nitrate and nitrite salts, in addition to the correlations plotted in Fig. 10 have been reported several times elsewhere (e.g., Janz et al. [48], Janz and Tomkins [49], among others). The heat capacity of equimolar Solar Salt was fixed in 1498 $\mathrm{J} \cdot \mathrm{kg}^{-1} \cdot{ }^{\circ} \mathrm{K}^{-1}$ by Tufeu et al. [147]. Although the correlated SAM data NREL [119] and the expression reported by Zavoico [113] are exactly the same, some differences can be found for temperature dependence if compared with Janz et al. [48]. Agreement among the different investigations analyzed (standard deviation about 148.99) suggests that the actualized values offered by SAM may be a good choice with a $2.36 \%$ of deviation from the global average, using the following expression:

$$
C p\left(\mathrm{~J} \cdot \mathrm{kg}^{-1} \cdot{ }^{\circ} \mathrm{K}^{-1}\right)=1396.044+0.172 \cdot \mathrm{T}\left({ }^{\circ} \mathrm{K}\right)
$$

Finally, correlations for the commercial Hitec ${ }^{\circledR}$ have been reported by Janz and Tomkins [49], Hoffman and Cohen [153] and Boerema et al. [118], using different expressions. Constant values were reported by Wu et al. [117] and Yang and Garimella [116], and this latter gives the same number as found in the SAM database. The computed standard deviation is 473.23 when using all reviewed data. A value of $C p=1560 \mathrm{~J} \cdot \mathrm{kg}^{-1} \cdot{ }^{\circ} \mathrm{K}^{-1}$ is suggested due to the agreement of recent proposals with early measurements, giving a $2.45 \%$ of deviation from average.

\section{Conclusions}

The future use of molten salts as coolants or HTF requires a previous checking of transport and thermal behaviors. The use of computational packages allows validation of preliminary designs, and
Table 5:

Heat capacity $\left(\mathrm{J} \cdot \mathrm{kg}^{-1} \cdot{ }^{\circ} \mathrm{K}^{-1}\right)$, suggested as constant value with temperature independence, for the reviewed salts. A function is only offered for the Solar Salt mixture.

\begin{tabular}{cccc}
\hline Salt mixture & $C p$ value & Stand. Dev. & $\%$ Dev. \\
\hline \hline FLiBe & 2385 & 191.89 & $5.26 \%$ \\
\hline FLiNaK & 1880 & 208.46 & $6.07 \%$ \\
\hline FLiNaBe & 2200 & 158.15 & $0.48 \%$ \\
\hline NaFNaB & 1506 & 263.08 & $6.56 \%$ \\
\hline FluZirK & 1000 & 9.43 & $5.36 \%$ \\
\hline CloKMag & 1155 & 140.41 & $4.42 \%$ \\
\hline Solar Salt & $1396.044+0.172 \cdot \mathrm{T}$ & 148.99 & $2.36 \%$ \\
\hline Hitec ${ }^{\circledR}$ & 1560 & 473.23 & $2.45 \%$ \\
\hline
\end{tabular}

even complete piping systems, reactors, or heat exchanger loops. Moreover, numerical simulations need verified physical properties as an input. This work intends to be a refined compendium of data, aiming to feed computer aided engineering designs. After a intensive review of the different reports and published data for eight different mixtures, several discrepancies have been found for some correlations, and a lack of data for certain salts. Deviations reveal that density is the best known property, but both viscosity as values for thermal properties, which in some cases are only based in theoretical models, show scattering. By this order, FLiBe, nitrates and $\mathrm{NaFNaB}$ mixtures have a global acceptable accuracy (less than $5 \%$ of global average deviations), followed by CloKMag, FLiNaK and FLiNaBe (less than $8 \%$ ). Although FluZirK has been recently suggested as suitable salt for certain applications, the level of knowledge about transport and thermal behavior is very short nowadays. Hence, the need of new studies is legitimated in order to obtain higher accuracy, mainly for thermal properties. Discussion about this latter parameters have shown that standard techniques must be refined or even developed in some particular cases, to avoid undesirable conditions or mechanisms which can disturb measuring procedures (such as interaction of sensors or dissolution of container materials). 


\section{References}

[1] C. Renault, M. Hron, R. Konings, D. E. Holcomb, GIF Symposium - Paris (France) - 9-10 September, 2009, p. 1.

[2] C. W. Forsberg, The Americas Nuclear Energy Symposium (ANES 2002). American Nuclear Society - Miami, Florida - October 16-18, 2002, p. 1.

[3] P. N. Haubenreich, J. R. Engel, Nuclear Applications \& Tecnology 8 (1970) 118-136.

[4] C. Le Brun, Journal of Nuclear Materials 360 (2007) $1-5$

[5] C. W. Forsberg, P. F. Peterson, D. F. Williams, Proceedings of 2005 International Conference on Advances in Nuclear Power Plants (ICAPP'05) - Seoul, KOREA - May 15-19, 2005, p. 1.

[6] C. W. Forsberg, Physics, Fuels, and Systems Cadarache, France - August 25-September 3, 2004 , p. 1.

[7] G. E. N.-IV International-Forum, GIF R\&D Outlook for Generation IV Nuclear Energy Systems, Generation IV International Forum (GIF), 2009.

[8] O. Beneš, C. Cabet, S. Delpech, P. Hosnedl, V. Ignatiév, R. Konings, D. Lecarpentier, O. Matal, E. Merle-Lucotte, C. Renault, J. Uhlir, Assessment of LIquid Salts for Innovative Applications (ALISIA). Deliverable (D-50). Review report on liquid salts for various applications, Euratom Research and Training Programme on Nuclear Energy, 2009.

[9] C. W. Forsberg, P. F. Peterson, H. Zhao, Journal of Solar Energy Engineering 129 (2007) 141-146.

[10] A. H. Slocum, D. S. Codd, J. Buongiorno, C. Forsberg T. McKrell, J.-C. Nave, C. N. Papanicolas, A. Ghobeity, C. J. Noone, S. Passerini, F. Rojas, A. Mitsos, Solar Energy 85 (2011) 1519-1529.

[11] S. M. Flueckiger, S. V. Garimella, Solar Energy 86 (2012) 1621-1631.

[12] S. Flueckiger, Z. Yang, S. V. Garimella, Applied Energy 88 (2011) 2098-2105.

[13] M. Eades, J. Flanders, T. Blue, X. Su, Nuclear and Emerging Technologies for Space 2012 - The Woodlands, Texas - Aerospace Nuclear Science and Technology Division of American Nuclear Society, March 21-23, 2012, p. 1.

[14] V. M. B. Nunes, M. J. V. Lourenço, F. J. V. Santos, C. A. de Castro, Journal of Chemical \& Engineering Data 48 (2003) 446-450.

[15] A. M. Weinberg, J. Accel. Plasma Res. 2 (1997) 23-26.

[16] R. C. Briant, A. M. Weinberg, Nuclear Science and Engineering 2 (1957) 797-803.

[17] H. G. MacPherson, Nuclear Science and Engineering 90 (1985) 374-380.

[18] M. W. Rosenthal, An Account of Oak Ridge National Laboratory's Thirteen Nuclear Reactors. ORNL/TM2009/181, Oak Ridge National Laboratory (ORNL), 2009 .

[19] C. B. Ellis, W. E. Thompson, The Aircraft Nuclear Propulsion Project. Quarterly progress report for period ending August 31, 1950. ORNL-858, Oak Ridge National Laboratory (ORNL), 1950.

[20] M. D. Grele, L. Gedeon (1954) 24.

[21] H. W. Hoffman, J. Lones, Fused Salt Heat Transfer.Part II. Forced convection heat transfer in circular tubes containing NaF-KF-LiF eutectic. ORNL-1977, Oak Ridge National Laboratory (ORNL), 1955.
[22] H. F. Poppendick, Physical Property Charts for Some Reactor Fuels, Coolants and Miscellaneous Materials. ORNL CF-52-8-212, Oak Ridge National Laboratory (ORNL), 1952.

[23] F. P. Hall, Herbert Insley, Journal of the American Ceramic Society 16 (1933) 455-567.

[24] F. P. Hall, Herbert Insley, Journal of the American Ceramic Society 21 (1938) 113-164.

[25] F. P. Hall, Herbert Insley, Phase diagrams for ceramists, American Ceramic Society, Columbus, OH, 1947.

[26] F. P. Hall, H. F. McMurdie, Phase diagrams for ceramists, American Ceramic Society, Columbus, OH, 1949.

[27] E. M. Levin, Phase diagrams for ceramists, Part 1, Phase Diagrams for Ceramists, Columbus, OH, American Ceramic Society, 1956.

[28] E. M. Levin, Phase diagrams for ceramists, Phase Diagrams for Ceramists, Part 2, American Ceramic Society, Columbus, OH, 1959.

[29] E. M. Levin, C. R. Carl R Robbins, H. F. McMurdie, M. K. Reser, Phase diagrams for ceramists, American Ceramic Society, Columbus, OH, 1964.

[30] J. E. Ricci, Guide to the Phase Diagrams of the Fluoride Systems. ORNL-2396, Oak Ridge National Laboratory (ORNL), 1958.

[31] R. E. Thoma, Phase diagrams of nuclear reactor materials. ORNL-2548, Oak Ridge National Laboratory (ORNL), 1959.

[32] W. R. Grimes, D. R. Cuneo, F. F. Blankenship, G. W. Keilholtz, H. F. Poppendick, M. T. Robinson, Chemical aspects of molten-fluoride-salt reactor fuels, Addison-Wesley Pub. Co., 1958.

[33] B. C. Blanke, E. N. Bousquet, M. L. Curtis, E. L. Murphy, Density and visosity of fused mixtures of lithium, berillyum, and uranium fluorides. MLM-1086, Mound Laboratory, Miamisburg, Ohio (MLM), 1956.

[34] W. R. Grimes, Molten Salt Reactor Program. Semiannual progress report for period ending July 31, 1964. ORNL-3708, Oak Ridge National Laboratory (ORNL), 1964.

[35] W. R. Grimes, Chemical research and development for Molten Salt Breeder Reactors. ORNL-TM-1853, Oak Ridge National Laboratory (ORNL), 1967.

[36] S. Cantor, Estimating specific heats and thermal conductivities of fused fluorides. Reactor Chemistry Division Annual Progress Report For Period Ending December 31, 1965. ORNL-3913, Oak Ridge National Laboratory (ORNL), 1965.

[37] S. Cantor, J. W. Cooke, A. S. Dworkin, G. D. Robbins, R. E. Thoma, G. M. Watson, Physical properties of Molten-Salt Reactor fuel, coolant, and flush salts. ORNL-TM-2316, Oak Ridge National Laboratory (ORNL), 1968.

[38] S. Cantor, Viscosity of molten salts. ORNL-4449 Quarterly Report, volume 4, Oak Ridge National Laboratory (ORNL), 1969.

[39] S. Cantor, W. T. Ward, C. T. Moynihan, Journal of Chemical Physics 50 (1969) 2874-2879.

[40] S. Cantor, Density and viscosity of several molten fluoride mixtures. ORNL/TM-4308, Oak Ridge National Laboratory (ORNL), 1973.

[41] H. F. McDuffie, H. E. McCoy, R. C. Robertson, D. Scott, R. E. Thoma, Density and voscosity of several molten fluoride mixtures. ORNL-TM-2696, Oak 
Ridge National Laboratory (ORNL), 1969.

[42] J. P. Sanders, A Review of Possible Choices for Secondary Coolants for Molten Salt Reactors. ORNL-718-10, Oak Ridge National Laboratory (ORNL), 1971.

[43] A. D. Kelmers, C. F. Baes, E. S. Bettis, J. Brynestad, S. Cantor, J. R. Engel, W. R. Grimes, H. E. McCoy, A. S. Meyer, Evaluation of Alternate Secondary (and Tertiary) Coolants for the Molten-Salt Breeder Reactor. ORNL/TM-5325, Oak Ridge National Laboratory (ORNL), 1976.

[44] M. D. Silverman, J. R. Engel, Survey of Technology for Storage of Thermal Energy in Heat Transfer Sal. ORNL/TM-5682, Oak Ridge National Laboratory (ORNL), 1977.

[45] G. J. Janz, F. W. Dampier, G. R. Lakshminarayanan, P. K. Lorenz, R. P. T. Tomkins, Molten salts: Volume 1, Electrical conductance, density, and viscosity data. NSRDS-NBS-15, U.S. National Bureau of Standards, 1968.

[46] G. J. Janz, C. G. M. Dijkhuis, G. R. Lakshminarayanan, R. P. T. Tomkins, J. Wong, Molten Salts: Volume 2. Section 1. Electrochemistry of Molten Salts, Gibbs Free Energies and Excess Free Energies from Equilibrium-Type Cells, Section 2. Surface Tension Data. NSRDS-NBS-28, U.S. National Bureau of Standards, 1969.

[47] G. J. Janz, C. B. Allen, J. R. Downey Jr, R. P. T. Tomkins, Physical properties data compilations relevant to energy storage. I. Molten salts: Eutectic Data. NSRDS-NBS-61(Pt.I), U.S. National Bureau of Standards, 1978.

[48] G. J. Janz, C. B. Allen, N. P. Bansal, R. M. Murphy, R. P. T. Tomkins, Physical properties data compilations relevant to energy storage II. Molten salts: data on single and multi-component salt systems. NSRDSNBS-61(Pt.II), U.S. National Bureau of Standards, 1979.

[49] G. J. Janz, R. P. T. Tomkins, Physical properties data compilations relevant to energy storage. IV Molten salts: Data on Additional Single and MultiComponent Salt Systems. NSRDS-NBS-61(Pt.IV), U.S. National Bureau of Standards, 1981.

[50] G. J. Janz, U. Krebs, H. F. Siegenthaler, R. P. T. Tomkins, Journal of Physical and Chemical Reference Data 1 (1972) 581-746.

[51] G. J. Janz, G. L. Gardner, U. Krebs, R. P. T. Tomkins, Journal of Physical and Chemical Reference Data 3 (1974) 1-115.

[52] G. J. Janz, R. P. T. Tomkins, C. B. Allen, J. R. and Downey Jr, G. L. Gardner, U. Krebs, S. K. Singer, Journal of Physical and Chemical Reference Data 4 (1975) 871-1178.

[53] G. J. Janz, R. P. T. Tomkins, C. B. Allen, J. R. and Downey Jr, S. K. Singer, Journal of Physical and Chemical Reference Data 6 (1977) 409-596.

[54] G. J. Janz, R. P. T. Tomkins, C. B. Allen, Journal of Physical and Chemical Reference Data 8 (1979) 125302.

[55] G. J. Janz, R. P. T. Tomkins, Journal of Physical and Chemical Reference Data 9 (1980) 831-1021.

[56] G. J. Janz, R. P. T. Tomkins, Journal of Physical and Chemical Reference Data 12 (1983) 591-815.

[57] G. J. Janz, Journal of Physical and Chemical Reference Data 17 (1988) 1-309.

[58] J. Fuller, M. Gaune-Escard, in: R. D. Rogers, K. R.
Seddon, S. Volkov (Eds.), Green Industrial Applications of Ionic Liquids, volume 0, Springer, 2003, pp. 275-294.

[59] D. F. Williams, L. M. Toth, Chemical considerations for the selection of the coolant for the Advanced High-Temperature Reactor. ORNL/GEN4/LTR-05011, Oak Ridge National Laboratory (ORNL), 2006.

[60] D. F. Williams, L. M. Toth, K. T. Clarno, Assessment of candidate molten salt coolants for the advanced high temperature reactor (AHTR). ORNL/TM-2006/12, Oak Ridge National Laboratory (ORNL), 2006.

[61] D. F. Williams, Assessment of candidate molten salt coolants for the NGNP/NHI Heat-Transfer Loop. ORNL/TM-2006/69, Oak Ridge National Laboratory (ORNL), 2006.

[62] D. F. Williams, Additional Physical Property Measurements and Assessment of Salt Compositions Proposed for the Intermediate Heat Transfer Loop. ORNL/GEN4/LTR-06-033, Oak Ridge National Laboratory (ORNL), 2006.

[63] P. Sabharwall, M. Ebner, M. Sohal, P. Sharpe, M. Anderson, K. Sridharan, J. Ambrosek, L. Olson, P. Brooks, Molten Salts for High Temperature Reactors: University of Wisconsin Molten Salt Corrosion and Flow Loop Experiments - Issues Identified and Path Forward. INL/EXT-10-18090, Idaho National Laboratory (INL), 2010.

[64] P. Calderoni, An Experimental Test Plan for the Characterization of Molten Salt Thermochemical Properties in Heat Transport Systems. INL/EXT-10-19921, Idaho National Laboratory (INL), 2010.

[65] M. S. Sohal, M. A. Ebner, P. Sabharwall, P. Sharpe, Engineering Database of Liquid Salt Thermophysical and Thermochemical Properties. INL/EXT-10-18297, Idaho National Laboratory (INL), 2010.

[66] D. Samuel, Molten Salt Coolants for High Temperature Reactors. A literature summary of key R\&D activities and challenges, IAEA Internship Report, 2009.

[67] A. L. Zherebtsov, V. V. Ignatiév, Physical properties of molten $\mathrm{Na}, \mathrm{Li}, \mathrm{Be} / \mathrm{F}$ mixtures. Experimental Mock-Up of Accelerator-Based Facility for Transmutation of Radioactive Waste and Conversion of Military Plutonium. ISTC Project \# 1606 Final Report, International Science and Technology Center (ISTC), Moscow, 2004.

[68] A. Hoshi, D. R. Mills, A. Bittar, T. S. Saitoh, Solar Energy 79 (2005) 332-339.

[69] D. LeBlanc, Nuclear Engineering and Design 240 (2010) 1644-1656.

[70] Nuclear-Energy-Agency OECD, Handbook on Leadbismuth Eutectic Alloy and Lead Properties, Materials Compatibility, Thermal-hydraulics and Technologies, 6195, OECD Publications, Paris, 2007.

[71] N. P. Siegel, Wiley Interdisciplinary Reviews (WIREs): Energy and Environment 1 (2012) 119-131.

[72] M. S. Sohal, P. Sabharwall, P. Calderoni, A. K. Wertsching, S. B. Grover, Conceptual Design of Forced Convection Molten Salt Heat Transfer Testing Loop. INL/EXT-19908, Idaho National Laboratory (INL), 2010.

[73] D. E. Holcomb, D. Ilas, A. L. Qualls, F. J. Peretz, V. K. Varma, E. C. Bradley, A. T. Cisneros, 2012 International Congress on the Advances in Nuclear Power Plants - Chicago - June 24-28, 2012, p. 1. 
[74] N. A. Anderson, P. Sabharwall, Nuclear technology 178 (2012) 335-340.

[75] J. W. Ambrosek, Molten Chloride Salts for Heat Transfer in Nuclear Systems, University of WisconsinMadison, 2011.

[76] M. V. Glazoff, Thermodynamic Assessment of Hot Corrosion Mechanisms of Superalloys Hastelloy N and Haynes 242 in Eutectic Mixture of Molten Salts KF and ZrF4. INL/EXT-12-24617, Idaho National Laboratory (INL), 2012.

[77] D. E. Holcomb, D. Ilas, V. K. Varma, A. T. Cisneros, R. P. Kelly, J. C. Gehin, Core and refueling design studies for the advanced high temperature reactor. ORNL/TM-2011/365, Oak Ridge National Laboratory (ORNL), 2011.

[78] D. T. Ingersoll, C. W. Forsberg, P. E. MacDonald, Trade Studies on the Liquid-Salt-Cooled Very HighTemperature Reactor: Fiscal Year 2006 Progress Report. ORNL/TM-2006/140, Oak Ridge National Laboratory (ORNL), 2006

[79] M. Schuller, F. Little, D. Malik, M. Betts, Q. Shao, J. Luo, W. Zhong, S. Shankar, A. Padmanaban, Molten Salt-Carbon Nanotube Thermal Energy Storage for Concentrating Solar Power Systems Final Report, Texas Engineering Experiment Station, 2012.

[80] O. Beneš, R. J. M. Konings, 3.13 - Molten Salt Reactor Fuel and Coolant, volume 3, Elsevier, Oxford, pp. 359389.

[81] P. Denholm, J. C. King, C. F. Kutcher, P. P. H. Wilson, Energy Policy 44 (2012) 301-311.

[82] D. E. Lacy, C. Coles-Hamilton, A. Juhasz, Selection of high temperature thermal energy storage materials for advanced solar dynamic space power systems. NASA Technical Memorandum 89886, Technical Report, National Aeronautics and Space Administration, Cleveland, OH (USA). Lewis Research Center, 1987.

[83] A. K. Misra, J. D. Whittenberger, Fluoride salts and container materials for thermal energy storage applications in the temperature range 973 to $1400 \mathrm{~K}$. NASA Technical Memorandum 89913. AIAA-87-9226, Technical Report, National Aeronautics and Space Administration, Cleveland, OH (USA). Lewis Research Center, 1987.

[84] J. C. Gomez, High-Temperature Phase Change Materials (PCM) Candidates for Thermal Energy Storage (TES) Applications. NREL/TP-5500-51446, National Renewable Energy Laboratory (NREL), 2011.

[85] Y. Li, Y. Zhang, M. Li, D. Zhang, Experimental Thermal and Fluid Science 44 (2013) 697-707.

[86] S. R. Greene, J. C. Gehin, D. E. Holcomb, J. J. Carbajo, D. Ilas, A. T. Cisneros, V. K. Varma, W. R. Corwin, D. F. Wilson, G. L. Yoder Jr, Others, Pre-Conceptual Design of a Fluoride-Salt-Cooled Small Modular Advanced High Temperature Reactor (SmAHTR). ORNL/TM-2010/199, Oak Ridge National Laboratory (ORNL), 2011.

[87] E. S. Kim, P. Sabharwall, N. Anderson, 2011 American Nuclear Society Annual Meeting - Hollywood, Florida - June 25-30, 2011, p. 1.

[88] O. Beneš, R. J. M. Konings, Journal of Fluorine Chemistry 130 (2009) 22-29.

[89] O. Beneš, R. Konings, S. Wurzer, M. Sierig, A. Dockendorf, Thermochimica Acta 509 (2010) 62-66.

[90] R. Ferri, A. Cammi, D. Mazzei, International Journal of Thermal Sciences 47 (2008) 1676-1687.
[91] T. Bauer, N. Breidenbach, N. Pfleger, D. Laing, M. Eck, Proceedings of World Renewable Energy Forum (WREF 2012) - Denver, USA - May 13-17, 2012, p. 1.

[92] D. S. Codd, A. H. Slocum, Proceedings of the ASME 2011 5th International Conference on Energy Sustainability - Washington, DC, USA - August 7-10, 2011, p. 1.

[93] B. D. Iverson, S. T. Broome, A. M. Kruizenga, J. G. Cordaro, Solar Energy 86 (2012) 2897-2911.

[94] A. Mao, J. H. Park, G. Y. Han, T. Seo, Y. Kang, Korean Journal of Chemical Engineering 27 (2010) 14521457.

[95] S. I. Cohen, T. N. Jones, Viscosity measurements on molten fluoride mixtures. ORNL-2278, Oak Ridge National Laboratory (ORNL), 1957.

[96] C. J. Barton, L. O. Gilpatrick, J. A. Bornmann, H. H. Stone, T. N. McVay, H. Insley, Journal of Inorganic and Nuclear Chemistry 33 (1971) 337-343.

[97] B. Vriesema, Aspects of molten fluorides as heat transfer agents for power generation, Delft University of Technology, Department of Mechanical Engineering, 1979.

[98] Y. Abe, O. Kosugiyama, A. Nagashima, Journal of Nuclear Materials 99 (1981) 173-183.

[99] J. Mlynariková, M. Chrenková, V. Danielik, V. Daněk, O. Matal, Monatshefte für Chemie - Chemical Monthly 139 (2008) 77-80.

[100] W. D. Powers, S. I. Cohen, N. D. Greene, Nuclear Science and Engineering 17 (1963).

[101] T. Korkut, A. Hançerlioğulları, Journal of Fusion Energy 31 (2011) 151-159.

[102] M. Chrenková, V. Daněk, A. Silný, V. Kremenetsky, E. Polyakov, Journal of Molecular Liquids 3 (2003) 213-226.

[103] J. Cibulkova, M. Chrenkova, R. Vasiljev, V. Kremenetsky, M. Boc, M. R. Materials, K. S. Centre, E. Section, Journal of Chemical \& Engineering Data 7 (2006) 984987.

[104] M. Salanne, C. Simon, P. Turq, P. A. Madden, Journal of Fluorine Chemistry 130 (2009) 38-44.

[105] J. Ambrosek, M. Anderson, K. Sridharan, T. Allen, Nuclear technology 165 (2009) 166-173.

[106] V. Khokhlov, V. Ignatiév, V. Afonichkin, Journal of Fluorine Chemistry 130 (2009) 30-37.

[107] S. R. Darienko, N. N. Kurbatov, S. P. Raspopin, Y. F. Chervinskii, Atomnaya Energiya 57 (1984) 122-123.

[108] S. R. Darienko, V. N. Desyatnik, S. F. Katyshev, Y. F. Chervinskii, Atomnaya Energiya 65 (1988) 223-224.

[109] S. R. Darienko, S. P. Raspopin, Y. F. Chervinskii, Atomnaya Energiya 62 (1987) 122-124.

[110] D. W. James, C. H. Liu, Journal of Chemical \& Engineering Data 8 (1963) 469.

[111] R. W. Carling, C. M. Kramer, R. W. Bradshaw, D. A. Nissen, S. H. Goods, R. W. Mar, J. W. Munford, M. M. Karnowsky, R. N. Biefeld, N. J. Norem, Molten Nitrate Salt Technology Development Status Report. SAND-80-8052, Technical Report March, Sandia National Laboratories, 1981.

[112] D. A. Nissen, Journal of Chemical \& Engineering Data 27 (1982) 269-273.

[113] A. B. Zavoico, Solar Power Tower Design Basis Document. SAND2001-2100, Technical Report July, Sandia National Laboratories, 2001.

[114] W. E. Kirst, W. M. Nagle, J. B. Castner, Transactions 
of the American Institute of Chemical Engineers 36 (1940) 371-394.

[115] P. G. Gaune, Journal of Chemical \& Engineering Data 27 (1982) 151-153.

[116] Z. Yang, S. V. Garimella, Solar Energy 84 (2010) 974985.

[117] Y.-T. Wu, C. Chen, B. Liu, C.-F. Ma, International Communications in Heat and Mass Transfer 39 (2012) 1550-1555.

[118] N. Boerema, G. Morrison, R. Taylor, G. Rosengarten, Solar Energy 86 (2012) 2293-2305.

[119] NREL, S.A.M. (System Advisor Model), 2012

[120] J. A. Boon, J. S. Wilkes, J. A. Laning, A Fundamental Electrochemical Investigation of Bromoaluminate and of Mixed Chloro-Bromoaluminate Room Temperature Molten Salt Systems. FJS RL-TR-89-0004, Technical Report, Frank J. Seiler Research Laboratory (FJSRL), 1989.

[121] R. W. Bradshaw, Viscosity of Multi-component Molten Nitrate Salts-Liquidus to $200^{\circ} \mathrm{C}$. SAND20101129, Technical Report March, Sandia National Laboratories, 2010.

[122] M. Salanne, C. Simon, P. Turq, P. A. Madden, The Journal of Physical Chemistry B 111 (2007) 46784684.

[123] V. N. Desyatnik, A. I. Nechaev, Y. F. Chervinskii, Zhurnal Prikladnoi Khimii (Leningrad) 54 (1981) 2310-2312.

[124] V. Ignatiév, A. Merzlyakov, V. Afonichkin, V. Khokhlov, A. Salyulev, in: 7th Information Exchange Meeting on Actinide and Fission Product Partitioning and Transmutation, Seventh Information Exchange Meeting on Actinide and Fission Product Partitioning and Transmutation, 14th-16th October, Jeju, Republic of Korea, Jeju (Republic of Korea), p. 1.

[125] L. J. Wittenberg, D. Ofte, C. F. Curtiss, Journal of Chemical Physics 48 (1968) 3253.

[126] B. Kubíková, V. Pavlík, I. Macková, M. Boča, Monatshefte für Chemie - Chemical Monthly 143 (2012) 1459-1462.

[127] R. Scheele, A. M. Casella, Assessment of the Use of Nitrogen Trifluoride for Purifying Coolant and Heat Transfer Salts in the Fluoride Salt-Cooled HighTemperature Reactor. PNNL-19793, Technical Report September, Pacific Northwest National Laboratory (PNNL), 2010.

[128] P. Sabharwall, E. S. Kim, A. Siahpush, N. Anderson, M. Glazoff, B. Phoenix, R. Mizia, D. Clark, M. Mckellar, M. W. Patterson, Feasibility Study of Secondary Heat Exchanger Concepts for the Advanced High Temperature Reactor. INL/EXT-11-23076, Technical Report September, 2011.

[129] P. Sabharwall, E. S. Kim, M. McKellar, N. Anderson, M. W. Patterson, Process Heat Exchanger Options for the Advanced High Temperature Reactor. INL-1121584, Idaho National Laboratory (INL), 2011.

[130] N. P. Siegel, R. W. Bradshaw, J. B. Cordaro, A. M. Kruizenga, in: ASME 2011 5th International Conference on Energy Sustainability, Parts A, B, and C, Asme, 2011, pp. 439-446.

[131] Y. Chen, Y. Wu, N. Ren, C. Ma, Science China Technological Sciences 54 (2011) 3022-3026.

[132] C. A. Nieto de Castro, in: TEMPMEKO 2004 - 9th Symposium on Temperature and Thermal Measure- ments in Industry and Science, Cavtat-Dubrovnik, Croatia, 2004, pp. 1-9.

[133] R. M. DiGuilio, A. S. Teja, International Journal of Thermophysics 13 (1992) 855-871.

[134] J. W. Cooke, L. G. Alexander, H. W. Hoffman, Molten-Salt Reactor Program Semmianual Progress Report for Period Ending August 31, 1968. ORNL4344, Technical Report, Oak Ridge National Laboratory (ORNL), 1968.

[135] K. Cornwell, Journal of Physics D: Applied Physics 4 (1971) 441-445.

[136] A. Turnbull, Australian journal of applied science 12 (1961) 30-41.

[137] A. Turnbull, Australian journal of applied science 12 (1961) 324-329.

[138] J. W. Cooke, H. W. Hoffman, J. J. J. Keyes, MoltenSalt Reactor Program Semmianual Progress Report for Period Ending February 28, 1969. ORNL-4396, 1969.

[139] Y. Kato, K. Furukawa, N. Araki, K. Kobayasi, High Temperatures-High PressuresHigh Pressures 15 (1983) 191-198.

[140] C. T. Ewing, J. R. Spann, R. R. Miller, Journal of Chemical \& Engineering Data 7 (1962) 246-250.

[141] M. V. Smirnov, V. A. Khokhlov, E. S. Filatov, Electrochimica acta 32 (1987) 1019-1026.

[142] W. R. Grimes, Nuclear Applications \& Tecnology 8 (1970) 137-155.

[143] V. V. Ignatiév, A. V. Merzlyakov, V. G. Subbotin, A. V. Panov, Y. V. Golovatov, Atomic Energy 101 (2006) 822-829.

[144] R. I. Olivares, Solar Energy 86 (2012) 2576-2583.

[145] J. McDonald, H. Ted Davis, The Journal of Physical Chemistry 74 (1970) 725-730.

[146] T. Omotani, Y. Nagasaka, A. Nagashima, International Journal of Thermophysics 3 (1982) 17-26.

[147] R. Tufeu, J. P. Petitet, L. Denielou, B. Le Neindre, International Journal of Thermophysics 6 (1985) 315330.

[148] T. Omotani, A. Nagashima, Journal of Chemical \& Engineering Data 29 (1984) 1-3.

[149] R. Santini, L. Tadrist, J. Pantaloni, P. Cerisier, International Journal of Heat and Mass Transfer 27 (1984) 623-626.

[150] T. B. Douglas, W. H. Payne, The Journal of Research of the National Institute of Standards and Technology 73 (1969) 479-485.

[151] W. D. Powers, G. C. Blalock, Enthalpy and heat capacity of halides. Aircraft Nuclear Propulsion Project Quarterly Progress Report For Period Ending September 10, 1953. ORNL-1609., Oak Ridge National Laboratory (ORNL), 1953.

[152] D. J. Rogers, T. Yoko, G. J. Janz, Journal of Chemical \& Engineering DataEngineering Data 27 (1982) 366367.

[153] H. W. Hoffman, S. I. Cohen, Fused salt heat transfer. Part III, Forced-convection heat transfer in circular tubes containing the salt mixture NaNO2-NaNO3KNO3. ORNL-2433, Technical Report, Oak Ridge National Laboratory (ORNL), 1960. 